\title{
Cofactor Engineering Redirects Secondary Metabolism and Enhances Erythromycin Production in Saccharopolyspora erythraea
}

\author{
Li, Xiaobo; Chen, Jun; Andersen, Joakim Mark; Chu, Ju; Jensen, Peter Ruhdal
}

Published in:

ACS Synthetic Biology

Link to article, DOI:

10.1021/acssynbio.9b00528

Publication date:

2020

Document Version

Publisher's PDF, also known as Version of record

Link back to DTU Orbit

Citation (APA):

Li, X., Chen, J., Andersen, J. M., Chu, J., \& Jensen, P. R. (2020). Cofactor Engineering Redirects Secondary Metabolism and Enhances Erythromycin Production in Saccharopolyspora erythraea. ACS Synthetic Biology, 9(3), 655-670. https://doi.org/10.1021/acssynbio.9b00528

\section{General rights}

Copyright and moral rights for the publications made accessible in the public portal are retained by the authors and/or other copyright owners and it is a condition of accessing publications that users recognise and abide by the legal requirements associated with these rights.

- Users may download and print one copy of any publication from the public portal for the purpose of private study or research.

- You may not further distribute the material or use it for any profit-making activity or commercial gain

- You may freely distribute the URL identifying the publication in the public portal 


\title{
Cofactor Engineering Redirects Secondary Metabolism and Enhances Erythromycin Production in Saccharopolyspora erythraea
}

\author{
Xiaobo Li, Jun Chen, Joakim M. Andersen, Ju Chu,** and Peter R. Jensen*
}

Cite This: ACS Synth. Biol. 2020, 9, 655-670

Read Online

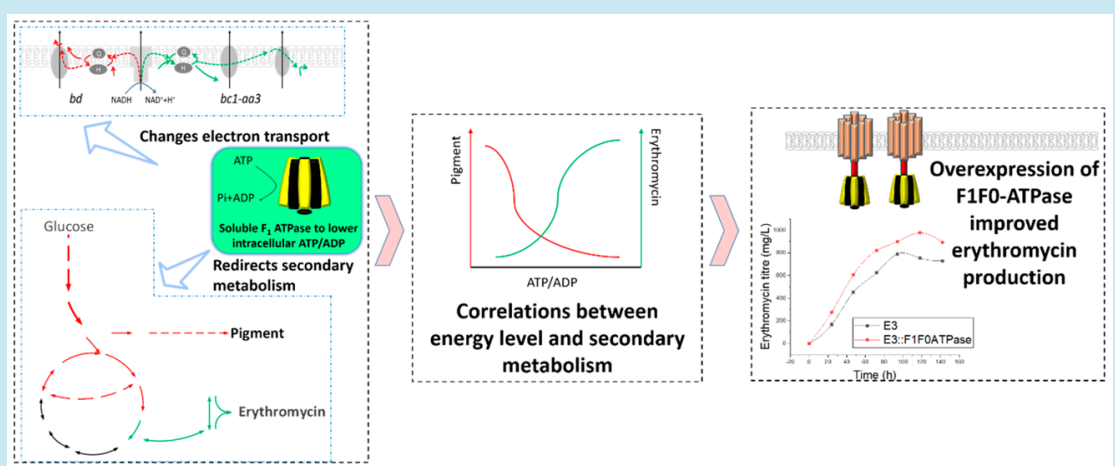

ABSTRACT: Saccharopolyspora erythraea is used for industrial erythromycin production. To explore the physiological role of intracellular energy state in metabolic regulation by $S$. erythraea, we initially overexpressed the $F_{1}$ part of the endogenous $F_{1} F_{0^{-}}$ ATPase in the high yielding erythromycin producing strain E3. The $\mathrm{F}_{1}$-ATPase expression resulted in lower $[\mathrm{ATP}] /[\mathrm{ADP}] \mathrm{ratios}$, which was accompanied by a strong increase in the production of a reddish pigment and a decreased erythromycin production. Subsequent transcriptional analysis revealed that the lower intracellular $[\mathrm{ATP}] /[\mathrm{ADP}]$ ratios exerted a pleotropic regulation on the metabolism of $S$. erythraea. The lower $[\mathrm{ATP}] /[\mathrm{ADP}]$ ratios induced physiological changes to restore the energy balance, mainly via pathways that tend to produce ATP or regenerate NADH. The $\mathrm{F}_{1}-\mathrm{ATP}$ ase overexpression strain exhibited a state of redox stress, which was correlated to an alteration of electron transport at the branch of the terminal oxidases, and $S$. erythraea channeled the enhanced glycolytic flux toward a reddish pigment in order to reduce $\mathrm{NADH}$ formation. The production of erythromycin was decreased, which is in accordance with the net ATP requirement and the excess NADH formed through this pathway. Partial growth inhibition by apramycin increased the intracellular $[\mathrm{ATP}] /[\mathrm{ADP}]$ ratios and demonstrated a positive correlation between $[\mathrm{ATP}] /$ $[\mathrm{ADP}]$ ratios and erythromycin synthesis. Finally, overexpression of the entire $\mathrm{F}_{1} \mathrm{~F}_{0}-\mathrm{ATPase}$ complex resulted in $28 \%$ enhanced erythromycin production and markedly reduced pigment synthesis in E3. The work illustrates a feasible strategy to optimize the distribution of fluxes in secondary metabolism.

KEYWORDS: ATPase, synthetic biology, redox regulation, energy metabolism, secondary metabolism, Saccharopolyspora erythraea

\begin{abstract}
A ctinomycetes are well-known as prolific producers of a variety of bioactive compounds. The increasing occurrence of antibiotic-resistant microbial pathogens has sparked growing attention toward the discovery of novel antibacterial compounds from actinomycetes. However, some novel antibacterial compounds are isolated from actinomycetes which are nonculturable under laboratory conditions. ${ }^{1}$ Fortunately, due to the evolutionary homology, the biosynthesis of both traditional and novel antibacterial compounds by actinomycetes relies on accumulation of similar precursors, such as propionyl-CoA and malonyl-CoA. ${ }^{2,3}$ Heterologous expression of natural product biosynthetic gene clusters in well-studied actinomycetes provides access to full biosynthesis of new natural products. ${ }^{4}$ Therefore, studies of the biosynthesis of antibiotics in paradigm model organisms, e.g., erythromycin in Saccharopolyspora erythraea (S. erythraea), are important for elucidating the
\end{abstract}

regulation mechanism involved in the biosynthesis of existing antibiotics and for future metabolic engineering of the heterologous production of new natural compounds.

Erythromycin A produced by S. erythraea is one representative of the macrolides antibiotics, and its derivatives also play vital pharmaceutical roles. ${ }^{5}$ The genome of S. erythraea contains at least 25 gene clusters for biosynthesis of known or predicted secondary metabolites, ${ }^{6}$ among which erythromycin and a

Received: December 23, 2019

Published: February 20, 2020 

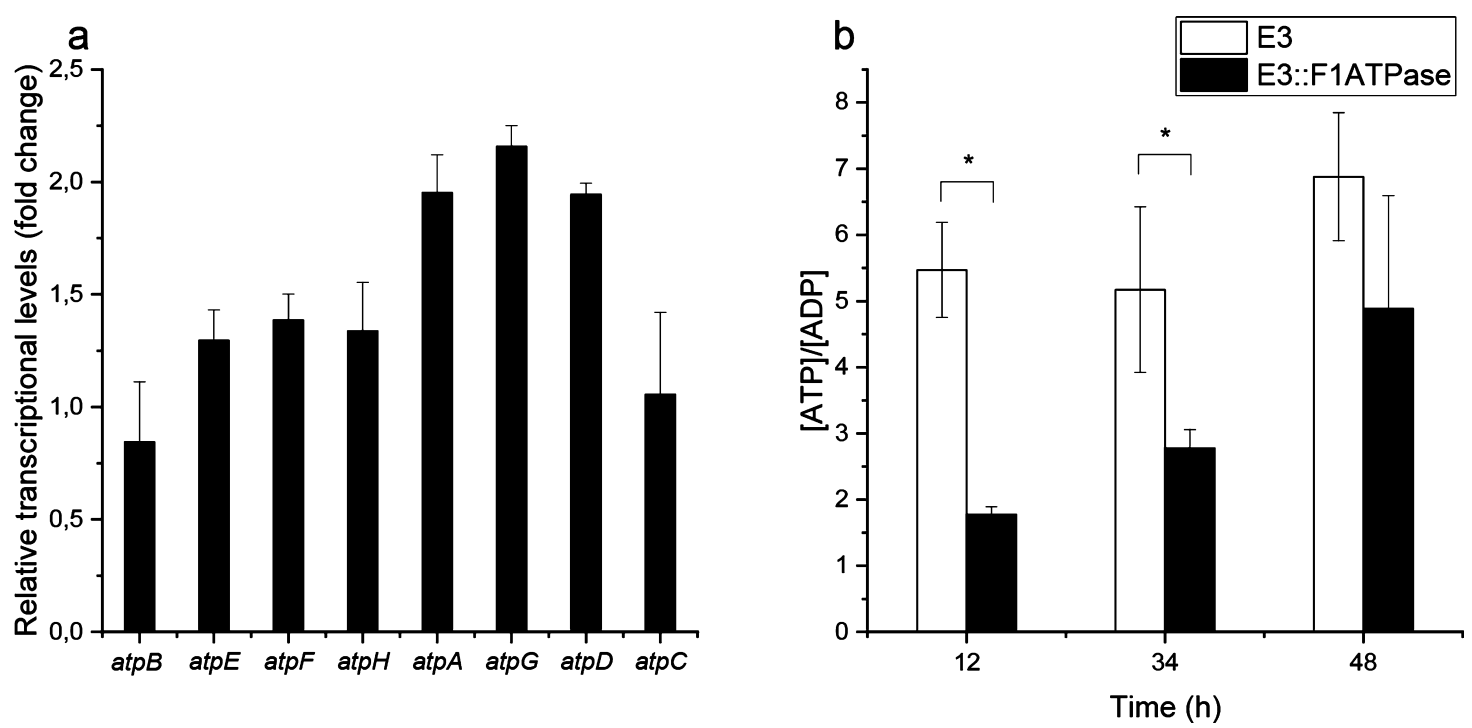

Figure 1. Overexpression of atpAGD caused lower $[\mathrm{ATP}] /[\mathrm{ADP}]$ ratios. (a) Quantitative RT-PCR (qRT-PCR) analysis of the transcription profiles of $\mathrm{F}_{1} \mathrm{~F}_{0}$-ATPase genes during the early exponential phase in minimal liquid medium. Relative transcript levels were obtained after normalization to the internal reference gene (16S rRNA). The relative expression values of each gene in parental strain E3 were set to 1.0 (arbitrary units). (b) Intracellular $[\mathrm{ATP}] /[\mathrm{ADP}]$ ratio in two strains, E3 and E3:: $\mathrm{F}_{1}$ ATPase. Error bars show the standard deviation from three independent experiments. $*, P$ value $<$ 0.05 .

reddish pigment represent the major ones. ${ }^{7}$ In industry, the reddish pigment derived from malonyl-CoA is considered as a byproduct which may increase the cost of erythromycin purification. Some of the previous metabolic engineering attempts did lead to either up- or down-regulation of the synthesis of several different secondary products but always in concert. ${ }^{8}$ With respect to S. erythraea, previous research has not yet achieved the goal to reduce pigment production and simultaneously enhance erythromycin production. ${ }^{7,9}$ In general, there is a lack of knowledge about the transcriptional regulation of the erythromycin biosynthesis gene cluster ${ }^{10}$ and new strategies are required to optimize the production of secondary products by $S$. erythraea.

Secondary metabolism is linked tightly to primary metabolism through the requirement for specific precursors and cofactors. ${ }^{11}$ Over the past decades, metabolic engineering of microbial metabolism to increase the supply of precursors through deletion or overexpression of genes encoding key enzymes has improved the production of some of these secondary metabolites. For instance, deletion of $m u t B$ (encoding the $\beta$ subunit of methylmalonyl-CoA mutase) in $S$. erythraea and deletion of $p f k A 2$ (encoding phosphofructokinase) or overexpression of the acetyl-CoA carboxylase in Streptomyces coelicolor significantly increased the synthesis of erythromycin or actinorhodin, respectively. ${ }^{11-13}$ However, few studies to date have focused on the effects of cofactors, i.e., ATP and NADH, on the secondary metabolism, despite the fact that in S. erythraea more than 200 reactions were associated with ATP metabolism according to genome-scale metabolic models. ${ }^{14,15}$

In $S$. erythraea, ATP is predominantly generated via membrane-localized $F_{1} F_{0}$-ATPase at the expense of a protonmotive force due to the electron transfer to oxygen, ${ }^{16}$ and sufficient oxygen uptake is known to be important for erythromycin synthesis. ${ }^{17}$ Some studies have provided clues as to the important role of the cofactors in antibiotic biosynthesis. For instance, a comparative transcriptomic study of the wildtype strain and a high-erythromycin-producing strain isolated after random mutagenesis also showed that genes encoding
$\mathrm{F}_{1} \mathrm{~F}_{0}$-ATPase are among the wide spectrum of differentially expressed genes, ${ }^{18}$ and a highly active oxidative metabolism was also observed in other antibiotic high-producing strains of Streptomyces. ${ }^{19}$ Another previous study showed that the addition of extracellular ATP to the culture medium had ambiguous effects on antibiotics production of $S$. coelicolor. ${ }^{20}$ However, the underlying mechanisms by which $S$. erythraea responds to changes in the cellular energy state are still not well understood.

The intracellular ATP level is well-known to play a regulatory role in controlling metabolic fluxes. For example, the intracellular ATP demand controls the glycolytic flux in E. coli and under certain conditions in S. cerevisiae ${ }^{21,22}$ and the success in enhancing glycolytic flux by increasing cellular ATP demand provided an alternative strategy to manipulate the flux through primary metabolism. When it comes to biotechnological applications, manipulation of intracellular ATP levels also affects the titer, productivity, yield, or even the spectrum of byproducts. ${ }^{23-26}$ These observations have prompted us to explore the physiological role of energy metabolism in secondary metabolism, with a view to find new ways to boost erythromycin production.

The native $\mathrm{F}_{1} \mathrm{~F}_{0}$-ATPase complex acts as an ATP synthase responsible for ATP production and consists of two main parts, the $F_{0}$ and $F_{1}$. The transmembrane $F_{0}$ part serves as a proton channel through which $\mathrm{H}^{+}$translocates, and the cytosolic $\mathrm{F}_{1}$ part catalyzes the synthesis of ATP from ADP and Pi. When the soluble $\mathrm{F}_{1}$ part is free from the membrane, it hydrolyzes ATP to $\mathrm{ADP}^{27}$ and it is therefore possible to alter the intracellular $[\mathrm{ATP}] /[\mathrm{ADP}]$ ratio by changing the expression of the $\mathrm{F}_{1}$ part of the $F_{1} F_{0}$-ATPase. ${ }^{28,29}$ In fact, by tuning the expression of $F_{1}$ ATPase, researchers found that the glycolysis could be uncoupled from biomass production without primary effects on other cellular processes. ${ }^{30}$ However, the earlier studies have focused solely on the effects on primary metabolism in E. coli and L. lactis, ${ }^{26,30-32}$ and less attention has been paid to organisms with extensive secondary metabolic routes.

In this study, in order to investigate the role of intracellular ATP alteration on metabolism of $S$. erythraea, we initially 
Table 1. Growth and Physiological Paramters of Parental Strain E3 and atpAGD Mutant E3:: $\mathrm{F}_{1}$ ATPase as Determined in Batch Culture $^{a}$

\begin{tabular}{lcccc}
\multicolumn{1}{c}{ strain } & $\mu_{\max }{ }^{b}\left(\mathrm{~h}^{-1}\right)$ & $Y_{\mathrm{x} / \mathrm{glc}}{ }^{c}(\mathrm{~g}$ of DCW $/ \mathrm{g})$ & $q_{\mathrm{glc}}{ }^{d}\left(\mathrm{~g} / \mathrm{g}\right.$ of DCW $\left.\mathrm{h}^{-1}\right)$ & $r_{\mathrm{O}_{2}}{ }^{e}\left(\% \mathrm{O}_{2} /(\mathrm{s} \cdot \mathrm{g} \mathrm{DCW})\right)$ \\
E3 & $0.12 \pm 0.01$ & $0.30 \pm 0.03$ & $0.08 \pm 0.01$ & $0.076 \pm 0.013$ \\
E3:: F F ATPase & $0.09 \pm 0.01$ & $0.22 \pm 0.02$ & $0.10 \pm 0.01$ & $0.046 \pm 0.009$
\end{tabular}

${ }^{a}$ Standard deviations were calculated from biological triplicates. ${ }^{b}$ Maximum specific growth rate. ${ }^{c}$ Biomass yield on glucose. ${ }^{d}$ Specific glucose uptake rate in the exponential phase. ${ }^{e}$ Specific oxygen uptake rate in the exponential phase.

decreased intracellular $[\mathrm{ATP}] /[\mathrm{ADP}]$ ratios by overexpressing the soluble $\mathrm{F}_{1}$-ATPase. After characterization of the cellular response to the alteration of the intracellular energy state at multiple levels, we propose a model which may explain the metabolic shifts in secondary metabolism and verified the model by increasing the $[\mathrm{ATP}] /[\mathrm{ADP}]$ ratio via inhibition with a sublethal concentration of an antibiotic. Finally, we showed that overexpressing the entire $\mathrm{F}_{1} \mathrm{~F}_{0}$-ATPase complex resulted in increased intracellular $[\mathrm{ATP}] /[\mathrm{ADP}]$ ratio and demonstrated a $28 \%$ enhancement of erythromycin production, as well as a marked decrease of pigment production, simultaneously.

\section{RESULTS AND DISCUSSION}

Overexpression of $F_{1}$-ATPase Decreased the Intracellular [ATP]/[ADP] Ratios in S. erythraea. In this study, we used a high-erythromycin-producing strain, E3, ${ }^{18}$ as the parental strain to explore the role of energy metabolism. E3 produces erythromycin at a comparable level with the one currently used in industry. ${ }^{13} \mathrm{~A}$ mutant strain, E3:: $\mathrm{F}_{1}$ ATPase, was constructed by overexpressing $\alpha, \beta$, and $\gamma$ (atpAGD, SACE_6282-6280) subunits of the native $\mathrm{F}_{1} \mathrm{~F}_{0}$-ATPase in S. erythraea E3. Transcription of the additional copy of $\mathrm{F}_{1}$-ATPase was promoted by the constitutive promoter ermE* ${ }^{3} .^{33}$ The transcription level of atpAGD was 1.9-fold in E3:: $\mathrm{F}_{1}$ ATPase compared to E3. The transcription of atpEFH was slightly higher, and that of $\operatorname{atpB} / \operatorname{atp} C$ remained at the same level in E3 (Figure 1a). We then measured the intracellular concentrations of ATP and ADP over a time course in batch culture and calculated the $[\mathrm{ATP}] /[\mathrm{ADP}]$ ratio. In general, $[\mathrm{ATP}] /[\mathrm{ADP}]$ ratios in $\mathrm{E} 3:: \mathrm{F}_{1} \mathrm{ATP}$ ase were constantly lower than those in $\mathrm{E} 3$. In the early exponential phase $(10 \mathrm{~h})$, the ratio for E3:: $\mathrm{F}_{1} \mathrm{ATPase}$ was one-third of that in E3 (Figure 1b). The ratio in E3:: $F_{1}$ ATPase increased steadily by 2.5 times from 1.8 to 4.9 as cells entered the stationary phase (at $48 \mathrm{~h}$ ). In contrast, the ratios in E3 remained around 6 throughout the experiment. The results confirmed the ATP hydrolysis due to expression of soluble $\mathrm{F}_{1}$-ATPase in S. erythraea.

Overexpression of $F_{1}$-ATPase Enhanced the Glycolytic Flux and $[\mathrm{NADH}] /\left[\mathrm{NAD}^{+}\right]$Ratios. In order to determine physiological changes caused by intracellular ATP perturbation, batch cultures in shake flasks were compared for both E3 and E3:: $F_{1}$ ATPase in the minimal medium (Table 1). The growth rate of E3:: $\mathrm{F}_{1} \mathrm{ATPase}$ decreased substantially by $22 \%$, and the biomass yield also decreased by $27 \%$. However, the specific glucose consumption rate for E3:: $\mathrm{F}_{1}$ ATPase increased by $24 \%$. This indicates that the glycolysis in $S$. erythraea has been uncoupled from the biomass production in E3:: $\mathrm{F}_{1}-\mathrm{ATP}$ ase due to the ATP deprivation. The enhanced glycolytic flux was in agreement with the response observed in E. coli and S.cerevisiae ${ }^{21,22}$ and may be caused by allosteric activation of some key enzymes, i.e., phosphofructokinase and pyruvate kinase in the glycolytic pathway at the low intracellular ATP level. ${ }^{26}$ For some obligately aerobic bacteria, the specific oxygen uptake rate $\left(r_{\mathrm{O}_{2}}\right)$ would usually increase if the glucose uptake rate $\left(r_{\text {glc }}\right)$ rises. ${ }^{34}$ Compared to $\mathrm{E} 3$, however, the $r_{\mathrm{O}_{2}}$ value of E3:: $F_{1}$ ATPase decreased by 38 and $9 \%$ in the exponential and stationary phases, respectively. A decreased oxygen uptake rate was correlated with a repressed NADH oxidation at the electron transport chain (ETC) which would indicate either a higher total amount of NADH generated or the existence of other pathways rather than ETC for NADH reoxidation in $\mathrm{E} 3:: \mathrm{F}_{1} \mathrm{ATPase}$ with respect to E3. The decreased respiration is likely to result in a lower membrane potential, which in turn would mean that the capability of the individual molecule of membrane-anchored $\mathrm{F}_{1} \mathrm{~F}_{0}$-ATPase to transfer $\mathrm{H}^{+}$across the plasma membrane is expected to decrease. ${ }^{35}$

The decreased respiration in E3:: $\mathrm{F}_{1}$ ATPase prompted us to explore the intracellular redox environment in both strains which is predominantly reflected in the intracellular [NADH]/ $\left[\mathrm{NAD}^{+}\right]$ratio. ${ }^{36}$ The concentrations of intracellular NADH and $\mathrm{NAD}^{+}$were measured, and $[\mathrm{NADH}] /\left[\mathrm{NAD}^{+}\right]$ratios were calculated over a time course (Figure 2 ). The $[\mathrm{NADH}] /$

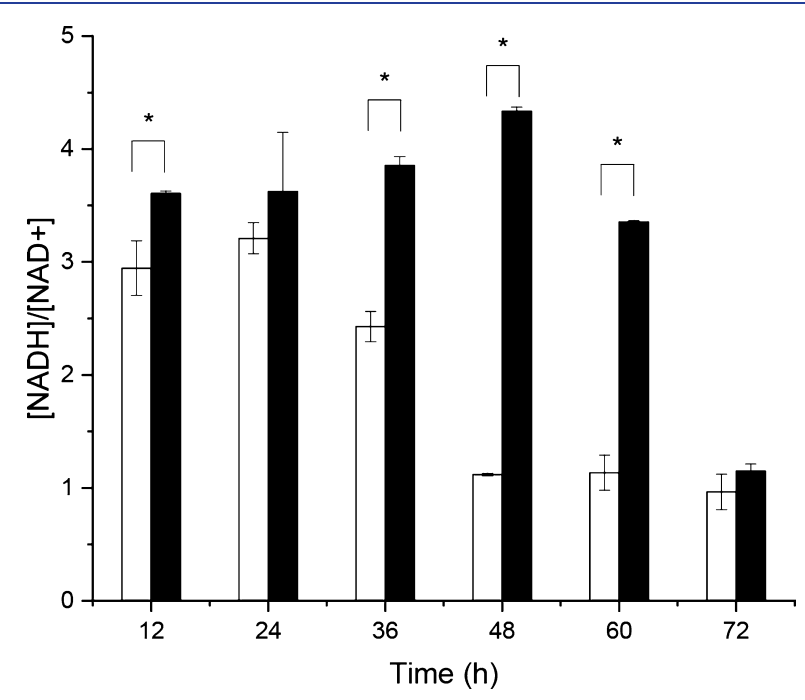

Figure 2. $\mathrm{F}_{1}$-ATPase (atpAGD) overexpression in E3:: $\mathrm{F}_{1}$ ATPase induced a redox stress that was reflected in the increasing $[\mathrm{NADH}] /$ $\left[\mathrm{NAD}^{+}\right]$ratio in the exponential phase. Intracellular $[\mathrm{NADH}] /\left[\mathrm{NAD}^{+}\right]$ ratio in $\mathrm{E} 3$ (white) and in E3:: $\mathrm{F}_{1}$ ATPase (black). Error bars show the standard deviation from three independent experiments. *, $P$ value < 0.01 .

$\left[\mathrm{NAD}^{+}\right]$ratio in E3 was approximately 3 before the midexponential phase and decreased to 1 in the stationary phase. The ratios in E3 were consistently and significantly lower than those in E3:: $\mathrm{F}_{1}$ ATPase. The ratio in E3:: $\mathrm{F}_{1}$ ATPase increased slightly from 3.5 to 4.3 in the exponential phase and then decreased. Reoxidizing $\mathrm{NADH}$ into $\mathrm{NAD}^{+}$is essential to achieve a redox balance, and although there may be a fast turnover of $\mathrm{NADH}$ or $\mathrm{NAD}^{+}, 37$ the persistently higher ratio indicates a state of redox stress until $72 \mathrm{~h}$ in E3:: $\mathrm{F}_{1}$ ATPase. These results are in accordance with the lower oxygen uptake 

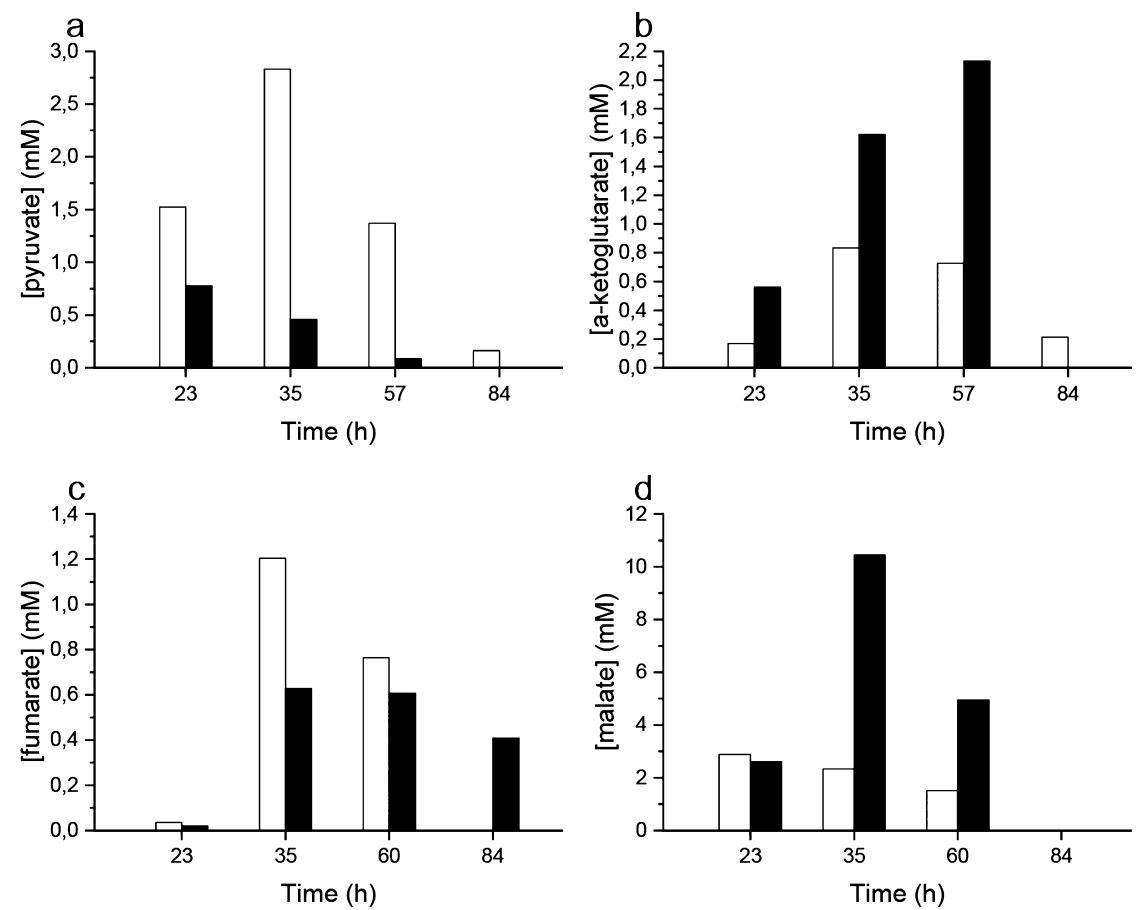

Figure 3. Concentration values of extracellular metabolites for E3 (white) and E3:: $\mathrm{F}_{1}$ ATPase (black): (a) pyruvate (PYR), (b) $\alpha$-ketaglutarate ( $\alpha$ $\mathrm{KG}$ ), (c) fumarate, (d) malate. Estimated relative flux modes around metabolites before $35 \mathrm{~h}$ were shown below each chart for E3 (white fill) and E3:: $F_{1} A T P a s e$ (black fill). Experiments were repeated in duplicate.

a

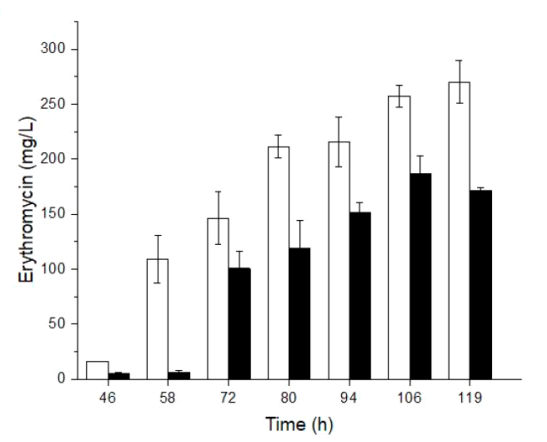

b
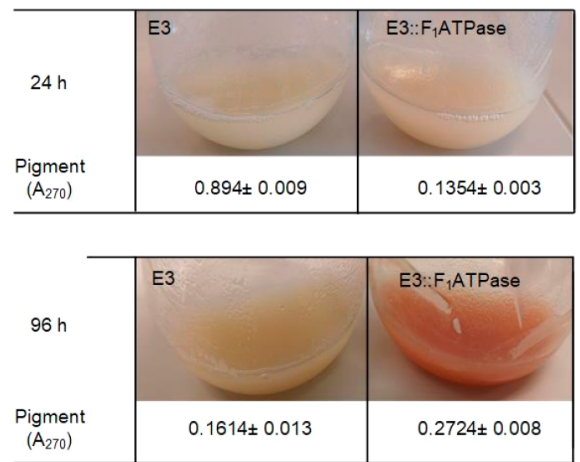

c

Day 3
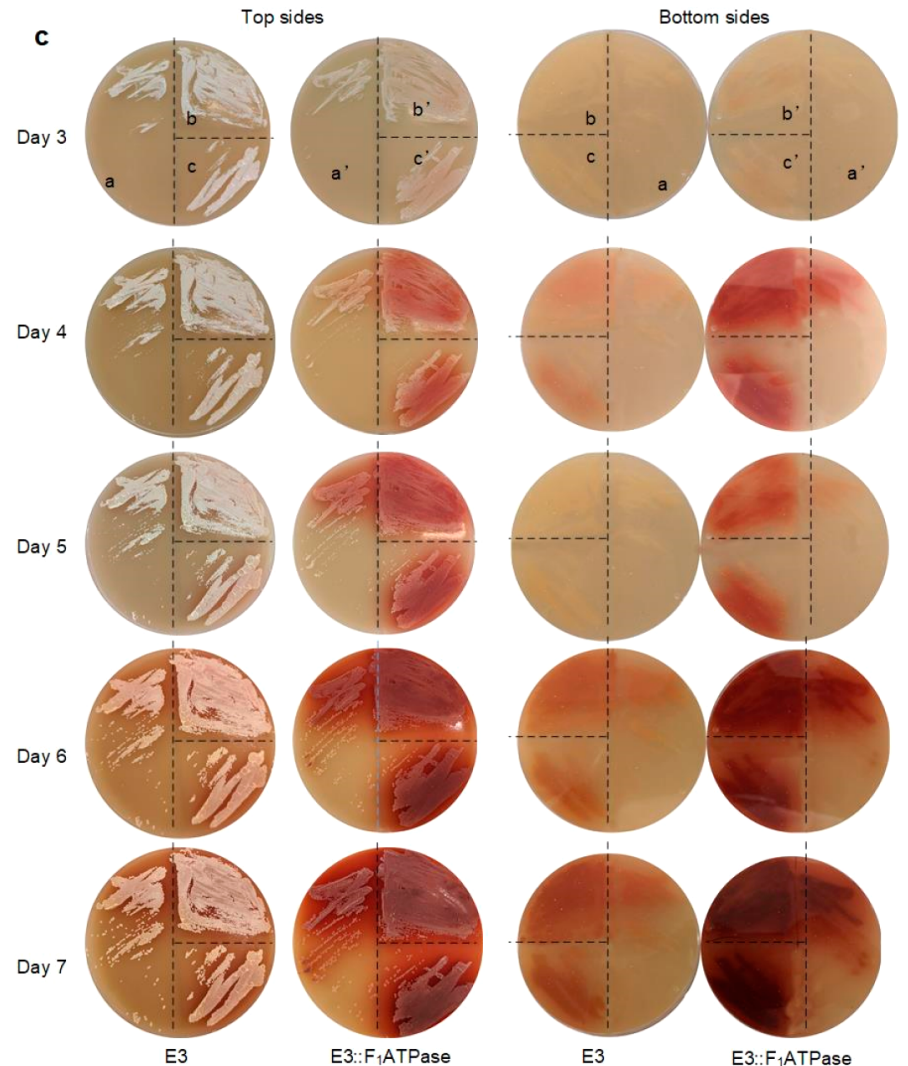

Figure 4. Quantification of secondary metabolites in E3 and E3:: $F_{1}$ ATPase. (a) Erythromycin titer in broth of E3 (white) or E3:: $F_{1}$ ATPase (black). Error bars show the standard deviation from three independent experiments. (b) Reddish pigment (7-O-rahmnosyl flaviolin) production at the middle exponential phase $(24 \mathrm{~h})$ and at the end $(96 \mathrm{~h})$ of culture in minimal liquid medium. Relative quantification of reddish pigment was represented by comparison of broth absorbance at $270 \mathrm{~nm}$, for which values are shown below the pictures. (c) Reddish pigment production and spore formation on $\mathrm{XM}$ agar medium. The lowercase letters with or without single quotes are on plates for identification of the same regions on top sides and bottom sides. 
a

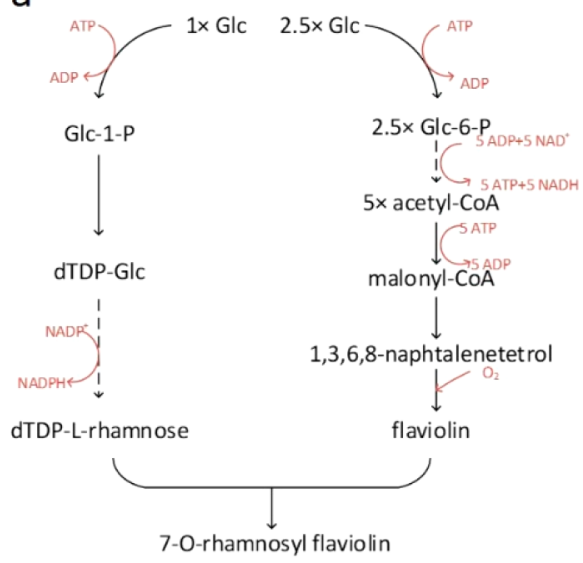

NADH availability: $1.43 \mathrm{~mol} / \mathrm{mol}$ glucose b

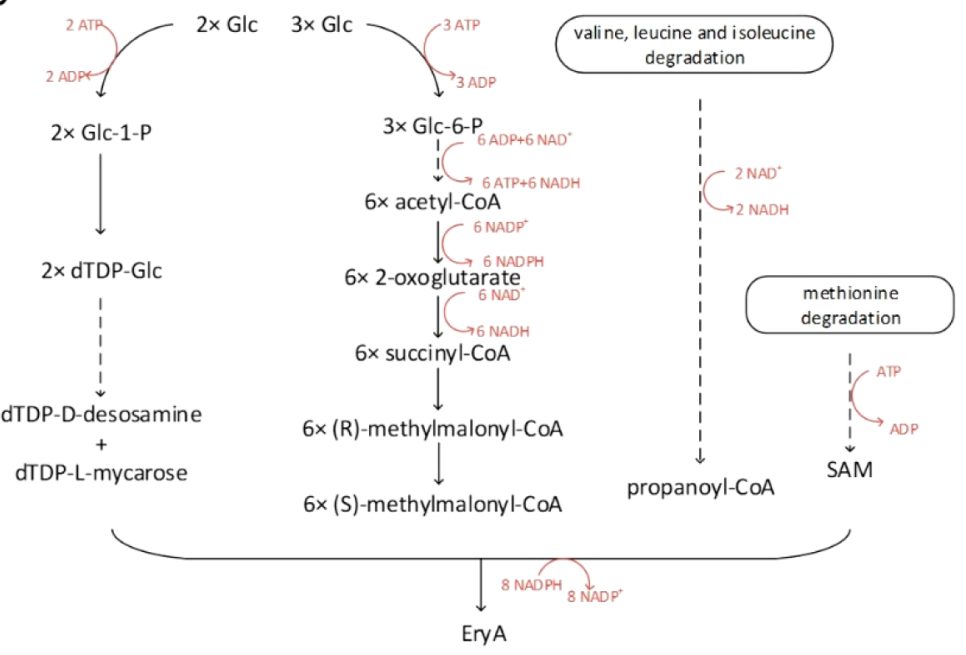

$\mathrm{NADH}$ availability: $3 \mathrm{~mol} / \mathrm{mol}$ glucose

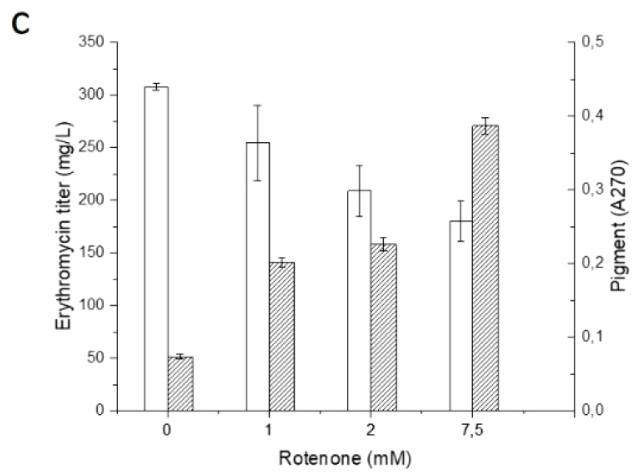

Figure 5. Addition of complex I (NADH dehydrogenase) inhibitor rotenone into E3 culture caused a same shifting trend as atpAGD overexpression. (a) Simplified synthesis pathways of the reddish pigment (polymer of 7-O-rhamnosyl flaviolin). (b) Simplified synthesis pathways of erythromycin. $\mathrm{NADH}$ availabilities of pigment or erythromycin synthesis based on 1 mol of glucose consumption were calculated and shown below the pathways. (c) Erythromycin (blank) and pigment (diagonal fill) production of E3 in culture with addition of different concentrations of rotenone. Error bars show the standard deviation from three independent experiments.

rate in E3:: $\mathrm{F}_{1}$ ATPase (Table 1), which indicates that the respiration rate in $\mathrm{E} 3:: \mathrm{F}_{1} \mathrm{ATPase}$ was insufficient to reoxidize the additional $\mathrm{NADH}$ produced.

Overexpression of $F_{1}$-ATPase Changed the Pattern of Byproducts. Cells were subsequently cultured in $1 \mathrm{~L}$ fermenters, and $\mathrm{pH}$ was monitored to observe overflow of intermediates from primary metabolism, which would acidify the broth. ${ }^{38}$ The $\mathrm{pH}$ of the broth of both strains remained almost stable around the initial value 6.7 during the first $12 \mathrm{~h}$ due to the $\mathrm{pH}$ buffer in the starting medium (Figure S1). At $12.5 \mathrm{~h}$, the $\mathrm{pH}$ in the E3:: $\mathrm{F}_{1}$ ATPase broth began to decrease, while the onset of the $\mathrm{pH}$ decrease was delayed to $15 \mathrm{~h}$ for E3. The early onset of $\mathrm{pH}$ drop for E3:: $\mathrm{F}_{1}$ ATPase correlated with its higher glucose uptake rate. The final $\mathrm{pH}$ of E3:: $\mathrm{F}_{1} \mathrm{ATP}$ ase broth was around 3.8, whereas it was about 4.1 for E3, suggesting changes in the extracellular metabolite profiles for the two strains.

We determined the concentration of intermediate organic acid overflow to the medium by HPLC analysis (Figure 3 ). In general, E3:: $\mathrm{F}_{1}$ ATPase secreted less pyruvate and fumarate, whereas more $\alpha$-ketoglutarate and malate were released. Typical overflow metabolites/byproducts, e.g., acetate or glycerol in $E$. coli or S. cerevisiae, ${ }^{27,39}$ were not detected in broth of these strains.
The concentration of an extracellular metabolite results from the balance between its production flux and its consumption flux in the cell (Figure 3). As E3:: $\mathrm{F}_{1}$ ATPase exhibited a higher glycolysis flux (Table 1), the lower pyruvate overflow in the E3:: $F_{1}$ ATPase broth meant that the consumption of intracellular pyruvate must be greater than that of E3. The increased overflow of $\alpha$-ketoglutarate and the decreased overflow of fumarate indicate that the E3:: $\mathrm{F}_{1} \mathrm{ATPase}$ strain had a reduced flux from $\alpha$ ketoglutarate to fumarate via the tricarboxylic acid (TCA) cycle, which in turn results in less accumulation of several intermediate metabolites, such as succinate and succinyl-CoA. The lower concentration of fumarate and the higher concentration of malate in E3:: $\mathrm{F}_{1}$ ATPase indicated a higher flux through the glyoxylate shunt. The patterns of extracellular metabolite profiles show intermediates of the TCA cycle and of the glyoxylate shunt, from which excess $\mathrm{NADH}$ equivalents would be generated.

ATP Perturbation Affected the Production of Erythromycin and a Reddish Pigment. We also observed the morphological phenotype and measured the erythromycin production for both strains (Figure 4). When grown on agar medium with glucose as a carbon source, E3:: $\mathrm{F}_{1}$ ATPase obtained a reddish appearance from day 3, which was 2 days earlier compared to E3. On day 7, the production of the reddish 
pigment by $\mathrm{E} 3:: \mathrm{F}_{1} \mathrm{ATPase}$ was markedly boosted compared to E3. When cultivated in minimal liquid medium, E3:: $\mathrm{F}_{1}$ ATPase started to produce pigment as early as from $24 \mathrm{~h}$ in the middle exponential phase, whereas for E3 production of the pigment and erythromycin began at $48 \mathrm{~h}$, i.e., close to the end of the exponential phase (Figure 4b). Moreover, compared to E3, E3:: $\mathrm{F}_{1}$ ATPase showed a $12 \mathrm{~h}$ lag in erythromycin production onset (Figure 4a). The final erythromycin titer of E3:: $F_{1}$ ATPase also decreased by approximately $20 \%$. These results showed that the intracellular ATP perturbation altered both the onset of secondary metabolite production and flux distribution within secondary metabolism.

In the context of industrial fermentation with S. erythraea for the purpose of erythromycin production, the reddish pigment is considered a byproduct. Erythromycin is assembled from propanoyl-CoA and methylmalonyl-CoA, both of which can be derived either from succinyl-CoA or valine/leucin/isoleucin degradation, ${ }^{40}$ whereas the synthesis of the reddish pigment starts from chain extension of malonyl-CoA, a process which is catalyzed by acetyl-CoA carboxylase. ${ }^{41}$ Evidence suggested that malonyl-CoA cannot be used for the biosynthesis of erythromycin in S. erythraea, ${ }^{7,9}$ probably due to the lack of enzymes to catalyze the conversion from malonyl-CoA to 3hydroxy-propionyl-CoA. Therefore, it is of interest to decipher the inverse alterations of the pigment and erythromycin production. During the stationary phase, the intracellular $[\mathrm{NADH}] /\left[\mathrm{NAD}^{+}\right]$ratios remained about 3 times higher in E3:: $F_{1} A T P a s e$ than in E3 (Figure 2). In principle, only half of the amount of $\mathrm{NADH}$ is generated along with the reddish pigment biosynthesis relative to erythromycin production with consuming equimolar glucose (Figure 5). We therefore hypothesize that the alteration of $[\mathrm{NADH}] /\left[\mathrm{NAD}^{+}\right]$ratios induced by ATP perturbation plays a regulatory role in flux distribution at the branch of acetyl-CoA, resulting in an altered pattern of secondary metabolites. To validate this, an inhibitor of complex I of the ETC, rotenone, ${ }^{42}$ was added into E3 culture at increasing concentrations to increase the intracellular $[\mathrm{NADH}] /\left[\mathrm{NAD}^{+}\right]$ ratios. The results showed that the addition of rotenone indeed stimulated pigment production slightly and simultaneously repressed erythromycin biosynthesis (Figure 5c).

The Activity of Enzymes around the Node of AcetylCoA Was Altered. To further validate the metabolic alteration at the branch of acetyl-CoA, enzymatic assays were performed using the whole cell extract of $S$. erythraea withdrawn in the exponential phase (Table 2). The activity of pyruvate

Table 2. Enzyme Activities in E3 and E3:: $F_{1}$ ATPase

\begin{tabular}{|c|c|c|c|}
\hline \multirow[b]{2}{*}{ enzyme } & \multicolumn{2}{|c|}{$\begin{array}{c}\text { activity } \\
(\mathrm{nmol} / \mathrm{min} / \mathrm{mg})^{a}\end{array}$} & \multirow{2}{*}{$\begin{array}{c}\text { ratio } \\
\left(\mathrm{E} 3:: \mathrm{F}_{1} \mathrm{ATPase} / \mathrm{E} 3\right)\end{array}$} \\
\hline & E3 & E3:: $F_{1}$ ATPase & \\
\hline pyruvate dehydrogenase & 74.76 & 212.11 & 2.84 \\
\hline citrate synthase & 623.30 & 1208.17 & 1.94 \\
\hline
\end{tabular}

dehydrogenase complex (PDH), a key enzyme complex in supplying acetyl-CoA, in cell extracts of E3:: $\mathrm{F}_{1}$ ATPase was 2.8 times that of E3, which could explain the lower pyruvate overflow in broth of E3:: $F_{1}$ ATPase. In contrast, the activity of citrate synthase (CIT) in E3:: $\mathrm{F}_{1}$ ATPase, which catalyzes the reaction from acetyl-CoA to citrate, was 1.9 times that of E3. This means that increase of the TCA cycle activity was lower than that in the glycolysis pathway, which corresponded to the hypothesis that $[\mathrm{NADH}] /\left[\mathrm{NAD}^{+}\right]$ratios correlated with ATP perturbation play a regulatory role in flux distribution. Table 2 shows that the TCA cycle cannot entirely accommodate the enhanced glycolytic flux. Therefore, S. erythraea had to redirect the enhanced glycolytic flux to other alternative routes besides the TCA cycle. The stimulated pigment production we observed in E3:: $\mathrm{F}_{1} \mathrm{ATPase}$ indicates that the total activity of acetyl-CoA carboxylase (ACC) is likely to be up-regulated in E3:: $\mathrm{F}_{1}$ ATPase.

Transcriptional Analysis Revealed an Important Regulatory Role of ATP in S. erythraea. To further elucidate effects of the ATP perturbation on the metabolism in $S$. erythraea, we analyzed the genome-wide transcription response to the ATP perturbation with samples withdrawn in the early exponential phase $(10 \mathrm{~h})$ and in the end of the exponential phase $(48 \mathrm{~h})$ for the E3 and E3:: $\mathrm{F}_{1}$ ATPase strains. Differentially expressed gene (DEG) analysis revealed that 172 genes were induced and 76 genes were repressed significantly in E3:: $F_{1}$ ATPase in the early exponential phase. At the point of the end of the exponential phase, 468 genes were induced and 295 genes were repressed significantly in E3:: $\mathrm{F}_{1} \mathrm{ATP}$ ase. In order to determine the cellular function affected by ATP perturbation, cluster orthologous group (COG) functional categories of DEGs were listed (Table 3). The cellular processes affected the most by ATP perturbation were energy production and conversion (C) followed by amino acid metabolism and transport (E), carbohydrate metabolism and transport (G), transcription $(\mathrm{K})$, replication and repair $(\mathrm{L})$, and secondary metabolites biosynthesis ( $\mathrm{Q}$ ) in proportion to the total gene numbers of each category. When the cell grew close to the stationary phase, more genes fell into the above-mentioned categories, particularly in transcription $(\mathrm{K})$, secondary metabolism (Q), and signal transduction (T). The difference of the transcription profiles shows broad regulatory functions of intracellular ATP in S. erythraea at the transcriptional level.

Next, more attention was paid on the transcriptional changes in the early exponential phase. Despite the fact that the onset of erythromycin production happened close to the stationary phase (Figure S2), the erythromycin biosynthesis gene cluster presents the highest transcription level at the early exponential phase. ${ }^{18,43}$ This was also observed in our RNA-sequencing data, where both E3 and E3:: $F_{1}$ ATPase exhibited a significant drop with respect to the transcription level of the erythromycin biosynthesis gene cluster. To incorporate directionality of gene expression, gene set analysis of DEGs for the sampling point in the early exponential phase was performed (Figure 6). The results showed that biological processes related to DNA and RNA activities ranked top among those cellular functions which were repressed most significantly in E3:: $\mathrm{F}_{1} \mathrm{ATPase}$. In contrast, cellular functions associated with redox environment such as expression of $\mathrm{NADH}$ dehydrogenase and oxidoreductase were stimulated most significantly in E3:: $\mathrm{F}_{1}$ ATPase. We then predicted reporter metabolites around which the most significant changes in expression occurred (Figure S3). The highest scoring reporter metabolite was L-glutamine, which indicates that the lower $[\mathrm{ATP}] /[\mathrm{ADP}]$ ratios stimulated nitrogen metabolism connecting tightly with $\alpha$-ketoglutarate. Combined with extracellular metabolite profiles (Figure 3c,d), it suggested that the amount of intracellular succinyl-CoA derived from $\alpha$-ketoglutarate was lower in E3:: $\mathrm{F}_{1} \mathrm{ATP}$ ase relative to E3, which would prevent additional $\mathrm{NADH}$ formation through this reaction. In addition, the higher overflow of $\alpha$-ketoglutarate and the more active glutamine metabolism in the exponential phase 
Table 3. Clusters of Orthologous Group (COG) Enrichment Analysis of Differentially Expressed Genes in E3:: $\mathrm{F}_{1}$ ATPase Compared with E3

\begin{tabular}{|c|c|c|c|c|c|c|}
\hline \multirow[b]{2}{*}{$\mathrm{COG}$} & \multirow[b]{2}{*}{ functional categories } & \multicolumn{2}{|c|}{ early exponential phase } & \multicolumn{2}{|c|}{$\begin{array}{l}\text { erythromycin synthesis onset } \\
\text { phase }\end{array}$} & \multirow{2}{*}{$\begin{array}{l}\text { total gene number in this } \\
\qquad \mathrm{COG}^{a}\end{array}$} \\
\hline & & up-regulated & down-regulated & up-regulated & down-regulated & \\
\hline $\mathrm{C}$ & energy production and conversion & 11 & 4 & 20 & 10 & 324 \\
\hline $\mathrm{D}$ & cell cycle control and mitosis & 0 & 0 & 1 & 2 & 31 \\
\hline $\mathrm{E}$ & amino acid metabolism and transport & 18 & 3 & 59 & 14 & 440 \\
\hline $\mathrm{F}$ & nucleotide metabolism and transport & 2 & 1 & 6 & 3 & 117 \\
\hline G & carbohydrate metabolism and transport & 11 & 2 & 15 & 12 & 429 \\
\hline $\mathrm{H}$ & coenzyme metabolism & 6 & 0 & 9 & 9 & 303 \\
\hline I & lipid metabolism & 4 & 2 & 10 & 11 & 311 \\
\hline $\mathrm{J}$ & translation & 1 & 0 & 2 & 1 & 209 \\
\hline $\mathrm{K}$ & transcription & 8 & 6 & 34 & 18 & 555 \\
\hline $\mathrm{L}$ & replication and repair & 2 & 4 & 12 & 13 & 116 \\
\hline M & cell wall/membrane/envelope biogenesis & 4 & 1 & 16 & 6 & 190 \\
\hline $\mathrm{O}$ & $\begin{array}{l}\text { post-translational modification, protein turnover, chaperone } \\
\text { functions }\end{array}$ & 3 & 4 & 9 & 8 & 154 \\
\hline $\mathrm{P}$ & inorganic ion transport and metabolism & 1 & 6 & 12 & 11 & 216 \\
\hline Q & $\begin{array}{l}\text { secondary metabolites biosynthesis, transport, and } \\
\text { catabolism }\end{array}$ & 8 & 1 & 14 & 13 & 244 \\
\hline $\mathrm{T}$ & signal transduction & 6 & 2 & 15 & 12 & 217 \\
\hline $\mathrm{V}$ & defense mechanism & 2 & 2 & 5 & 5 & 115 \\
\hline \multirow[t]{2}{*}{ S } & function unknown & 29 & 19 & 118 & 63 & 185 \\
\hline & TOTAL & 116 & 57 & 352 & 211 & 4156 \\
\hline
\end{tabular}

${ }^{a}$ Data is based on the IMG web resource (https://img.jgi.doe.gov/cgi-bin/pub/main.cgi?section=TaxonDetail\&page=cogs\&cat=cat\&taxon_oid= 2576861650).

may have induced a fake nitrogen-rich signal, which would repress erythromycin biosynthesis from the point of signal transduction view. ${ }^{44}$ Among the top 15 metabolites, ubiquinol/ ubiquinone and acceptor/acceptor (reduced) were all linked to $\mathrm{NADH}$ directly, which agreed well with the intracellular redox change we observed.

From the metabolic point of view, the genome-scale model of S. erythraea ${ }^{15}$ and iPATH ${ }^{45}$ were utilized to illustrate the general impact of ATP perturbation on central carbon metabolism (Table S1). The lower intracellular ATP level induced transcription of genes in the Embden-Meyerhof-Parnas (EMP) pathway and in the TCA cycle when the cells were in the early exponential phase. For instance, transcription of SACE_1218 encoding pyruvate dehydrogenase and SACE_0632 encoding citrate synthase in E3:: $\mathrm{F}_{1}$ ATPase was 1.6 times and 1.4 times of those in E3, respectively. An important gene, SACE 5639 (mutB, encoding the $\beta$ subunit of methylmalonyl-CoA mutase) was transcriptionally repressed in E3: $\mathrm{F}_{1} \mathrm{ATPase}$ with respect to E3. It suggested that the higher $\alpha$-ketaglutarate pool in E3:: $\mathrm{F}_{1} \mathrm{ATPase}$ stimulated the nitrogen metabolism around glutamine/glutamate rather than accumulating more methylmalonyl-CoA for erythromycin synthesis. Expression of most genes engaged in the pentose phosphate pathway was repressed, resulting in less NADPH accumulation, which exerted a negative effect on erythromycin biosynthesis. ${ }^{46}$ Transcription of genes involved in pigment biosynthesis including SACE_0500, SACE_3856, and SACE_7038 was significantly induced. SACE_0500 encodes a transcriptional regulator, DasR, which positively controls the pigment production. ${ }^{9}$ SACE_3856 and SACE_7038 encode acetylCoA carboxylase to convert acetyl-CoA into the pigment precursor malonyl-CoA. Transcriptional stimulation of these three genes was likely to be responsible for the pigment overproduction in E3:: $\mathrm{F}_{1} \mathrm{ATPase}$.
Overexpression of $\mathrm{F}_{1}$-ATPase Alters the Electron Transport. Under aerobic conditions, the respiration coupled with the transfer of electrons from $\mathrm{NADH}$ to $\mathrm{O}_{2}$ would be the predominant way to reoxidize $\mathrm{NADH}$ in $S$. erythraea, as evidenced by the high rank of transcriptional stimulation of genes encoding electron carriers among all of the $\operatorname{NAD}(\mathrm{H})$ related genes (Table S2). Moreover, the $\mathrm{NADH}$ dehydrogenase and the succinate dehydrogenase, i.e., complexes I and II in ETC, were up-regulated (Figure 7). There are two kinds of terminal oxidases with different oxygen affinities and different proton pumping abilities in the ETC of S. erythraea. ${ }^{16}$ In E3:: $F_{1} A T P a s e$, genes encoding $b c_{1}-a a_{3}$ oxidase were repressed, whereas genes encoding the $b d$-type oxidase were stimulated significantly. This indicates that the overexpression of $\mathrm{F}_{1^{-}}$ ATPase caused electron transport shifting at the branch point of the terminal oxidases from the $b c_{1}-a a_{3}$ complex which exhibits a lower oxygen affinity to the $b d$-type terminal oxidase which exhibits a higher oxygen affinity. ${ }^{47,48}$ The switch of electron transport was correlated with the lower respiration rate in E3:: $\mathrm{F}_{1}$ ATPase, which implied a decreased NADH reoxidization by aerobic respiration. ${ }^{49}$ The two types of terminal oxidases exhibit different efficiencies in generating the electrochemical gradient of protons coupled to electron transport: $b c_{1}-a a_{3}\left(6 \mathrm{H}^{+} /\right.$ $\left.2 \mathrm{e}^{-}\right)$and $b d\left(2 \mathrm{H}^{+} / 2 \mathrm{e}^{-}\right){ }^{48}$ Therefore, E3::F $\mathrm{F}_{1}$ ATPase reoxidized only a portion of the excess $\mathrm{NADH}$ through ETC and probably without increasing the membrane potential.

The global physiological response in E3:: $F_{1}$ ATPase was accompanied by energy deficiency and redox stress. Previous research showed that, when cellular ATP hydrolysis was enhanced in $E$. coli, the glucose consumption rate increased due to allosteric activation, ${ }^{26}$ which inevitably led to the elevation of $\mathrm{NADH}$ formation through the glycolytic pathway. Transcriptional alterations of the electron transport chain and the corresponding decreased respiration in E3:: $\mathrm{F}_{1}$ ATPase 
Color Key

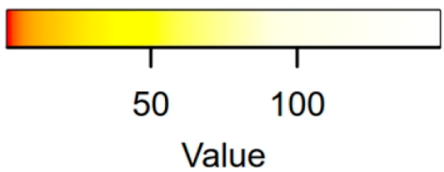

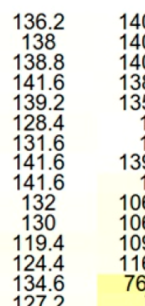

\subsection{667}

140.667

138.667

145

145

115

106.833
106.833

09.167

16.167

76.167

79
96.833
1385

96.833
138.5
63.333

138.5
63.333
56.833

56.833
38.333
30.167

25.5

31.33

14
48

29.667
91.5

91.5
76.5
79.833

79.833

89.5
89.5

53

9.143
9.143
7

89.6

50

60.5

105.667
127.833

18.833

89.857
88

104

98.429

53.571

53.143
64.429
54.143

63.286

59

\begin{tabular}{ccc}
\hline 83.143 & 60.167 & 29.6 \\
82.857 & 75.5 & 14.8 \\
81.857 & 70.167 & 23.8 \\
84 & 78 & 24.2 \\
136.286 & 126.833 & 14.4
\end{tabular}

\begin{tabular}{ccc}
\hline 83.143 & 60.167 & 29.6 \\
82.857 & 75.5 & 14.8 \\
81.857 & 70.167 & 23.8 \\
84 & 78 & 24.2 \\
136.286 & 126.833 & 14.4
\end{tabular}

\begin{tabular}{|c|c|c|}
\hline 83.143 & 40.167 & 29.6 \\
82.857 & 75.5 & 14.8 \\
81.857 & 70.167 & 23.8 \\
84 & 78 & 24.2 \\
136.286 & 126.833 & 14.4
\end{tabular}

\begin{tabular}{lll|l}
14.429 & 9.167 & 14.4 \\
16.429 & 10.5 & 21.4
\end{tabular}

\begin{tabular}{l|l|l}
5.429 & 10.5 & 31.8 \\
\hline & 8.167 & 28.4
\end{tabular}

- n

.167
9.833

16.4
13.2

13.2
16.2

(

22.833

39.8
29.6

$\begin{array}{ll}53.833 & 32.2 \\ 30.167 & 29.2\end{array}$

$\begin{array}{ll}571 & 40.333\end{array}$

\begin{tabular}{ccc}
7 & 4.333 & 3.6 \\
49.286 & 26.833 & 59.8 \\
\hline
\end{tabular}

\begin{tabular}{lll}
43.714 & 28.833 & 69 \\
\hline & & 69.8
\end{tabular}

\begin{tabular}{l|l|l}
30.143 & 17.667 & 72.6 \\
20.571 & 11.833 & 68
\end{tabular}

72.6
68
72.6
59.8

$\begin{array}{lll}57 & 12.667 & 59.8 \\ & 120.5 & 116\end{array}$

$\begin{array}{ll}53.571 & 103.5\end{array}$

106.667

1122.167

112.4
122.8
122.6

133.6
137.4
127.8

139.5

135.167

127.8

141.8

129.4

90

48.667

101.5

68.4
137

142.4

141

138.6

143.4

144.6

144.4

130.4
132.2
129.2

133.6
134.8
102

130.8

98.2
102.2

102.2
84.2

136
106.8
133.2
133.2
133

tructural constituent of..

ribosome

regulation of transcripti..

equence-specific DNA bin.

protein serine/threonine.

intracellular signal transduction

ATP binding

protein phosphorylation

protein kinase activity

potassium ion transport

DNA recombination

RNA binding

nucleic acid binding

phosphorylation

erine-type endopeptidase...

ptidase...

GTPase activity

histidine biosynthetic pr..

GTP binding

negative regulation of tr..

protein folding

base-excision repair

cobalamin biosynthetic pr..

chromosome segregation

DA binding

RNA aming

aminoacyl-tRNA ligase act.

cytoplasm

nucleotide binding

aminopeptidase activity

carbon-nitrogen ligase ac.

peptidase activity

protein metabolic process

glycine catabolic process

pyridoxamine-phosphate ox.

iosynthetic process

sequence-specific DNA bin..

molybdenum ion binding

phosphopantetheine bindin...

nickel cation binding

glycerol metabolic proces..

cation binding

ectron carrier activity

A dehydrogenase ac...

ilasm

drohydrate metabolic pr..

drolase activity
se activity

NAD binding

ADH dehydrogenase (ubiqu...

xidoreductase activity

metabolic process

oxidation-reduction proce...

exida

xtracellular region

.

catalytic activity

4 iron

nitrogen compound metabol.

cell redox homeostasis

soprenoid biosynthetic p..

transition metal ion bind...

glycolysis

gctivity

$147.667 \quad 133$

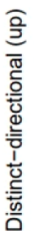

Figure 6. Gene set analysis (GSA) of DEGs (E3 VS E3:: $\mathrm{F}_{1}$ ATPase) of samples taken in the early exponential phase based on gene ontology (GO) function annotation. Gene set consensus scores are shown in the heatmap. The consensus score is the mean rank of $P$-value given to each gene set by the different unique GSA runs. A gene set with a low consensus score value has a high significance of transcriptional change. The nondirectional class disregards the direction of gene regulation. In the mixed-directional class, a gene set can be found significant in both the up-regulated and downregulated part. The distinct-directional class detects gene sets that are significantly affected by differential expression only in one distinct direction. The suffix “(dn)" means gene sets up-regulated in E3:: $F_{1}$ ATPase, whereas “(up)" means gene sets down-regulated in E3.

indicated that the excess $\mathrm{NADH}$ caused a persistent redox stress instead of an enhanced ATP generation through oxidative phosphorylation. It thus appears that metabolic shifts to avoid excess $\mathrm{NADH}$ formation occurred rather than an enhanced 


\section{a}

\begin{tabular}{|c|c|}
\hline \multicolumn{2}{|c|}{ Log2(Fold change) } \\
\hline \multirow{14}{*}{$\begin{array}{c}\text { complex I } \\
\text { (NADH dehydrogenase) }\end{array}$} & SACE_6889 \\
\hline & SACE_6890 \\
\hline & SACE_6891 \\
\hline & SACE_6892 \\
\hline & SACE_6893 \\
\hline & SACE_6894 \\
\hline & SACE_6895 \\
\hline & SACE_6896 \\
\hline & SACE_6897 \\
\hline & SACE_6898 \\
\hline & SACE_6899 \\
\hline & SACE_6900 \\
\hline & SACE_6901 \\
\hline & SACE_6902 \\
\hline \multirow{4}{*}{$\begin{array}{c}\text { complex II } \\
\text { (succinate dehydrogenase) }\end{array}$} & SACE_1168 \\
\hline & SACE_1169 \\
\hline & SACE_1170 \\
\hline & SACE_1171 \\
\hline \multirow{4}{*}{$\begin{array}{c}\text { complex II } \\
\text { (alternative succinate } \\
\text { dehydrogenase) }\end{array}$} & SACE_6582 \\
\hline & SACE_6583 \\
\hline & SACE_6584 \\
\hline & SACE_6585 \\
\hline \multirow{3}{*}{$\begin{array}{l}\text { cytochrome bc1 complex (III } \\
\text { bc1 type) }\end{array}$} & SACE_1685 \\
\hline & SACE_1686 \\
\hline & SACE_1687 \\
\hline \multirow{8}{*}{$\begin{array}{c}\text { cytochrome c (complex IV } \\
\text { aa3) }\end{array}$} & SACE_1187 \\
\hline & SACE_1312 \\
\hline & SACE_1678 \\
\hline & SACE_1684 \\
\hline & SACE_2161 \\
\hline & SACE_2168 \\
\hline & SACE_4988 \\
\hline & SACE_7041 \\
\hline complex III & SACE_0142 \\
\hline bd type & SACE_0143 \\
\hline
\end{tabular}

b

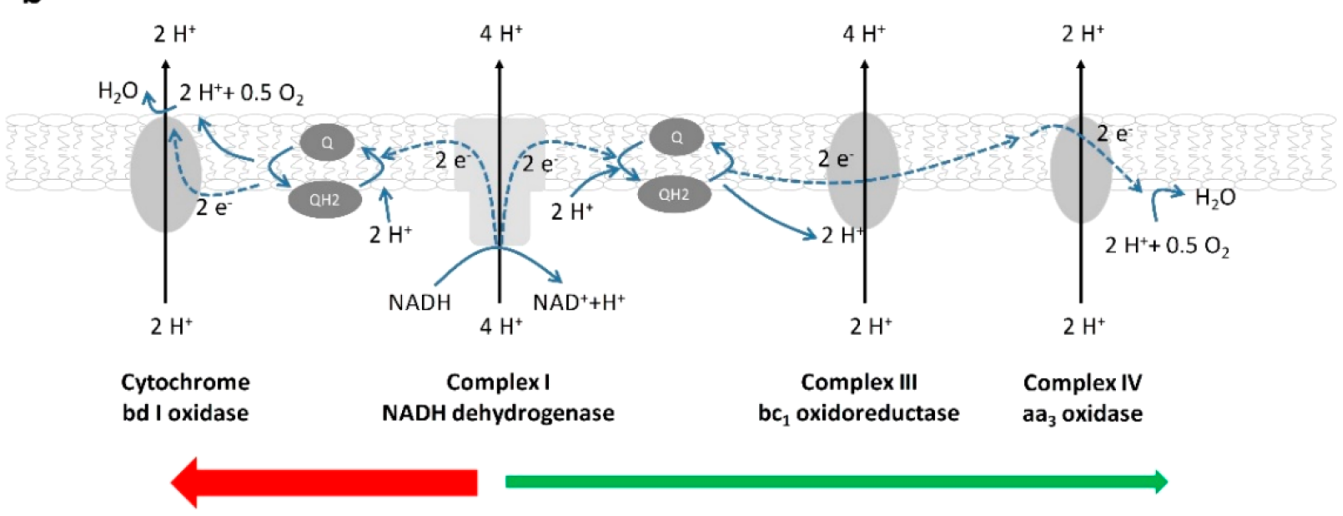

Figure 7. Transcriptional change of genes in ETC. (a) Transcription heatmap of genes encoding all complexes in ETC. (b) Schematic map of electron transport alteration in ETC. Arrows below the picture indicate the up-regulated (red) or down-regulated (green) electron transport route.

respiration for $\mathrm{NADH}$ oxidation in $S$. erythraea. The excess $\mathrm{NADH}$ in $\mathrm{E} 3:: \mathrm{F}_{1}$ ATPase drives substantial acetyl-CoA to the pigment biosynthesis rather than to the TCA cycle or glyoxylate shunt pathway compared to E3. Similarly, most of the genes involved in the $\mathrm{NADH}$-forming valine/leucin/isoleucin degradation were also repressed at the transcriptional level. These metabolic shifts all prevent more $\mathrm{NADH}$ formation. Consequently, despite the enhanced glycolytic flux induced by the lower $[\mathrm{ATP}] /[\mathrm{ADP}]$ ratios in $\mathrm{E} 3:: \mathrm{F}_{1} \mathrm{ATPase}$, this did not result in a higher accumulation of precursors for erythromycin but rather the higher overflow of $\alpha$-ketoglutarate and lower overflow of fumarate (Figure 3).

In this work, the addition of NADH dehydrogenase inhibitor, rotenone, repressed erythromycin production. Besides, structural alterations of ETC in S. coelicolor were shown to affect cell differentiation and antibiotic production. ${ }^{48,50}$ Therefore, it suggests that tuning the intracellular redox environment by either engineering ETC or NADH-dependent reactions would be a feasible strategy to regulate secondary metabolism in $S$. erythraea as well. Noteworthy, the correlation or the balance 

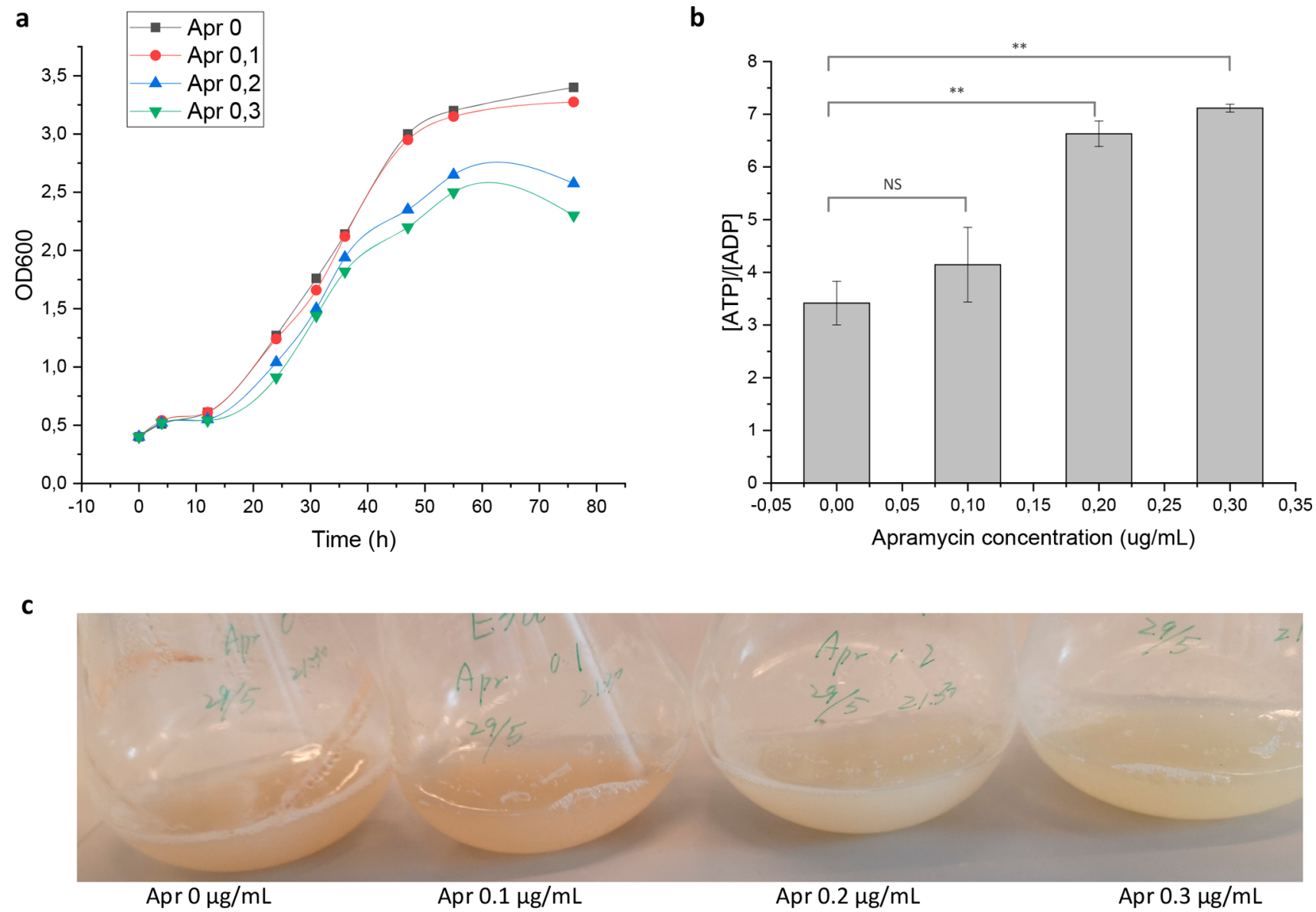

Figure 8. Effects of antibiotic addition on S. erythraea. (a) Growth curves of S. erythraea E3 with addition of different initial concentrations ( $\mu \mathrm{g} / \mathrm{mL})$ of apramycin (Apr). Experiments were repeated in duplicate. (b) Intracellular $[\mathrm{ATP}] /[\mathrm{ADP}]$ ratio of samples from cultures with apramycin. Cells were harvested at $14 \mathrm{~h}$ for $[\mathrm{ATP}] /[\mathrm{ADP}]$ ratio measurements. Error bars show the standard deviation from three independent experiments. NS, no significance; $* *, P$ value $<0.01$. (c) Pigment production in cultures with apramycin.

between redox environment and ATP generation must be taken into account. ${ }^{51}$

Enhancement of Intracellular [ATP]/[ADP] Ratios Stimulated Erythromycin Synthesis and Reduced Reddish Pigment Production. The observed physiological response in E3:: $F_{1} A T P a s e$ raises the question of whether increased $[\mathrm{ATP}] /[\mathrm{ADP}]$ ratios might enhance erythromycin production. One way to increase intracellular $[\mathrm{ATP}] /[\mathrm{ADP}]$ ratios is to reduce ATP consumption by the addition of sublethal concentrations of antibiotics to inhibit growth partially. Sublethal concentrations of apramycin were therefore added into the liquid culture of E3, which is sensitive to the apramycin, at the beginning of the fermentation. The growth of E3 was inhibited slightly (Figure 8a). Indeed, the intracellular [ATP]/ [ADP] ratios increased gradually from 3.2 in culture without apramycin to 7.1 in culture with $0.3 \mu \mathrm{g} / \mathrm{mL}$ apramycin (Figure $8 \mathrm{~b})$. Interestingly, the pigment production was repressed (Figure $8 \mathrm{c}$ ), while the specific erythromycin production relative to cell density was increased (Figure 9a).

The erythromycin titer decreased in different cultures, as the amount of apramycin increased which resulted in the lower production of biomass. Addition of antibiotics into the culture is therefore not the way forward for increasing erythromycin, but the results still inspired us to seek an industrially applicable way to boost erythromycin synthesis in the industrial strain. We therefore constructed a strain, E3: $: \mathrm{F}_{1} \mathrm{~F}_{0} \mathrm{ATPase}$, by over- expressing the entire $\mathrm{F}_{1} \mathrm{~F}_{0}$-ATPase complex in an attempt to increase the intracellular $[\mathrm{ATP}] /[\mathrm{ADP}]$ ratio. Indeed, the intracellular $[\mathrm{ATP}] /[\mathrm{ADP}]$ ratio in $\mathrm{E} 3: \mathrm{F}_{1} \mathrm{~F}_{0} \mathrm{ATP}$ ase was 11.4 in the exponential phase, which was twice that of E3 (Figure 9b). Intriguingly, compared to the parental strain E3, E3:: $\mathrm{F}_{1} \mathrm{~F}_{0} \mathrm{ATPase}$ produced a less reddish pigment (Figure 9c) and the final erythromycin titers of E3:: $\mathrm{F}_{1} \mathrm{~F}_{0} \mathrm{ATPase}$ were enhanced by around $28 \%$ both in the minimal liquid medium and in the complex medium (Figure 9d).

The observed phenotype of the $\mathrm{F}_{1} \mathrm{~F}_{0}$-ATPase overexpressing strain stressed the importance of high $[\mathrm{ATP}] /[\mathrm{ADP}]$ ratios for erythromycin production. In addition to erythromycin production, the cell growth, maintenance, intracellular environment control, substrate transport, and product export also require an adequate supply of ATP. ${ }^{52}$ For instance, increasing ATP levels in baker's yeast enhanced biosynthesis of $S$ adenosylmethionine, ${ }^{31}$ which is one of the essential precursors for erythromycin production in S. erythraea. Our results extend our knowledge about the correlation between energy level and antibiotic production in accordance with some previous research. For example, an energy deficiency due to disruption of polyphosphate kinase gene ( $p p k)$ exerted a positive effect on actinorhodin production in Streptomyces lividans, ${ }^{53,54}$ which appears to challenge the observations in our present study. However, rafamycin production was repressed when $p p k$ was disrupted in Amycolatopsis mediterranei. ${ }^{55}$ It is noteworthy that 

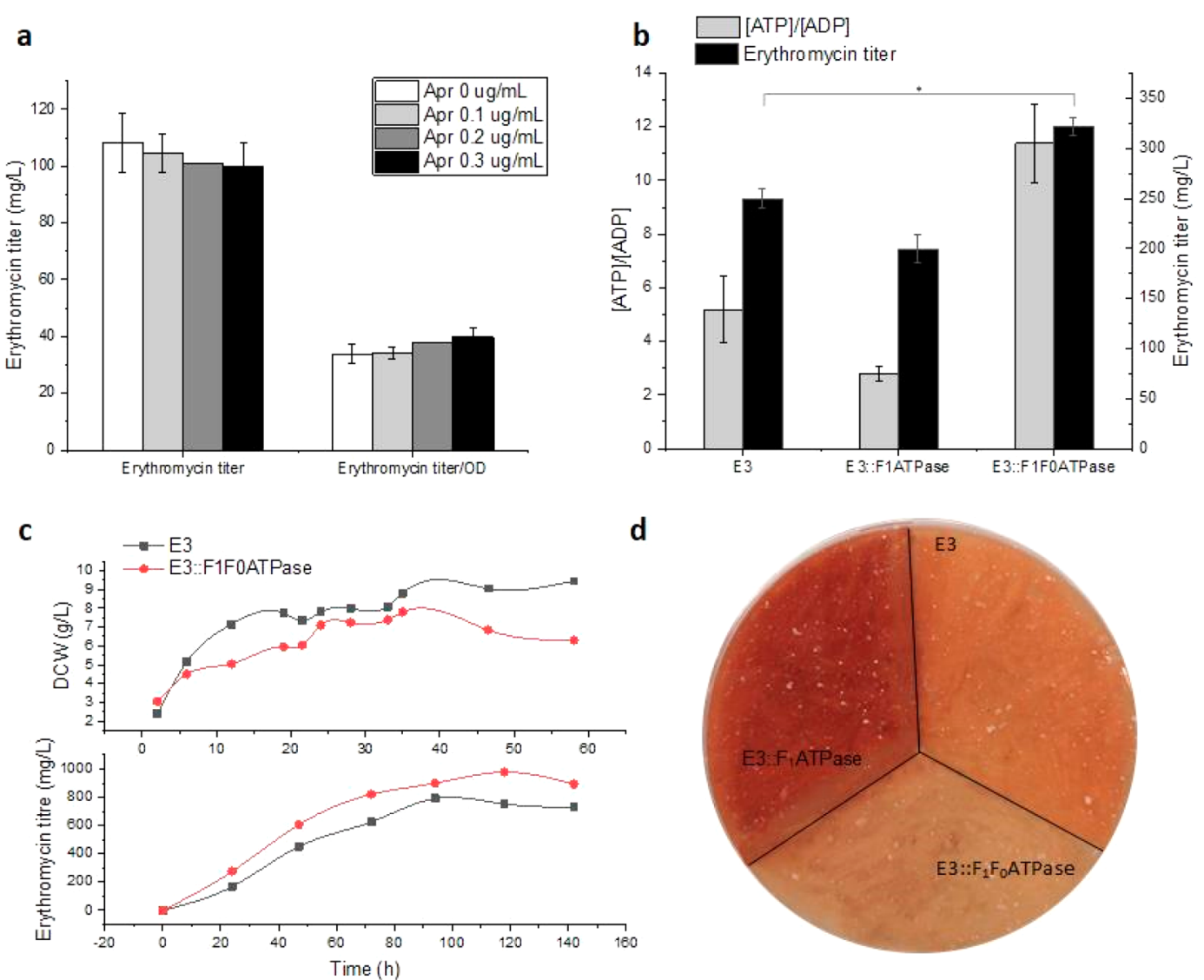

Figure 9. Enhancement of the intracellular $[\mathrm{ATP}] /[\mathrm{ADP}]$ ratio induced erythromycin production and repressed pigment production. The strain overexpressing the entire $\mathrm{F}_{1} \mathrm{~F}_{0}-\mathrm{ATPase}$ is $\mathrm{E} 3: \mathrm{\textrm {F } _ { 1 }} \mathrm{F}_{0} \mathrm{ATPase}$. (a) Erythromycin titers in cultures with different initial concentrations of apramycin (Apr). (b) Intracellular $[\mathrm{ATP}] /[\mathrm{ADP}]$ ratios and erythromycin titers of samples from liquid culture of E3, E3:: $\mathrm{F}_{1} \mathrm{ATP}$ ase, and E3:: $\mathrm{F}_{1} \mathrm{~F}_{0} \mathrm{ATP}$ ase at $34 \mathrm{~h}$. Error bars show the standard deviation from three independent experiments. (c) Growth curve and erythromycin titers of samples from complex medium in $250 \mathrm{~mL}$ flasks. Experiments were repeated in duplicate. (d) Pigment production on XM medium after 6 days of incubation at $34^{\circ} \mathrm{C}$. Strain names are marked on plates. *, $P$-value $<0.05$.

biosynthesis of rafamycin requires the same precursors, i.e., methylmalonyl-CoA and propanoly-CoA, which are also used for erythromycin synthesis.

In addition, the model suggested in this study (Figure 10) is also consistent with results in previous research, ${ }^{56}$ in which lower intracellular $[\mathrm{ATP}] /[\mathrm{ADP}]$ ratios induced by chemical supplementation stimulated the production of some antibiotics. Those antibiotics have a common precursor malonyl-CoA that is the same precursor of the reddish pigment in S. erythraea. Thus, the pigment overproduction in E3:: $\mathrm{F}_{1} \mathrm{ATPase}$ suggests that biosynthesis of some other secondary metabolites may benefit from lower intracellular $[\mathrm{ATP}] /[\mathrm{ADP}]$ ratios. Together, these results suggest that manipulations of intracellular energy state can be exploited as a strategy to alter the production of antibiotics, not only in S. erythraea but also in other streptomycetes. The general impact of manipulations of energy state on the production of a particular secondary metabolite may further be predicted by stoichiometric calculations about the $\mathrm{ATP}$ requirement and $\mathrm{NADH}$ formation by the relevant secondary metabolic pathways.

\section{CONCLUSIONS}

This study characterized the overall physiological response of an industrial strain of $S$. erythraea toward the perturbation of intracellular ATP, and the overall response to lower [ATP]/ $[\mathrm{ADP}]$ ratios was summarized in the schematic map (Figure 10).
The results showed a positive correlation between intracellular energy level and erythromycin synthesis, which suggests novel metabolic engineering strategies to improve production of erythromycin and to repress pigment synthesis simultaneously in S. erythraea. We hypothesized and also validated that the metabolic shift of enhanced carbon flux to the reddish pigment synthesis in E3:: $\mathrm{F}_{1} \mathrm{ATPase}$ appears to relieve the redox stress, as evidenced by slight $[\mathrm{NADH}] /\left[\mathrm{NAD}^{+}\right]$divergence which $\mathrm{E} 3$ and E3:: $F_{1}$ ATPase exhibited at the end of culture (Figures 1 and 2). Eventually, the metabolic shift to pigment synthesis in response to ATP perturbation and a fake nitrogen-rich signal caused by the higher $\alpha$-ketaglutarate pool probably inhibiting the accumulation of ( $\mathrm{p}$ )ppGpp ${ }^{44,57}$ contributed to the decrease of erythromycin production.

The alteration of pigment and erythromycin synthesis indicated that manipulations of intracellular energy state could serve as strategies for simultaneous regulation of multiple secondary metabolism owing to the broad regulatory role of ATP perturbation. Synthesis of secondary metabolites is usually catalyzed by a series of enzymes encoded by genes in a cluster with transcriptional regulation in most cases. Manipulation of respective transcription regulators of pigment or erythromycin biosynthesis genes induced synergetic production of these two secondary metabolites. ${ }^{9,58}$ Even the disruption of the key gene for pigment synthesis, which resulted in eliminating pigment production totally, could not increase erythromycin produc- 


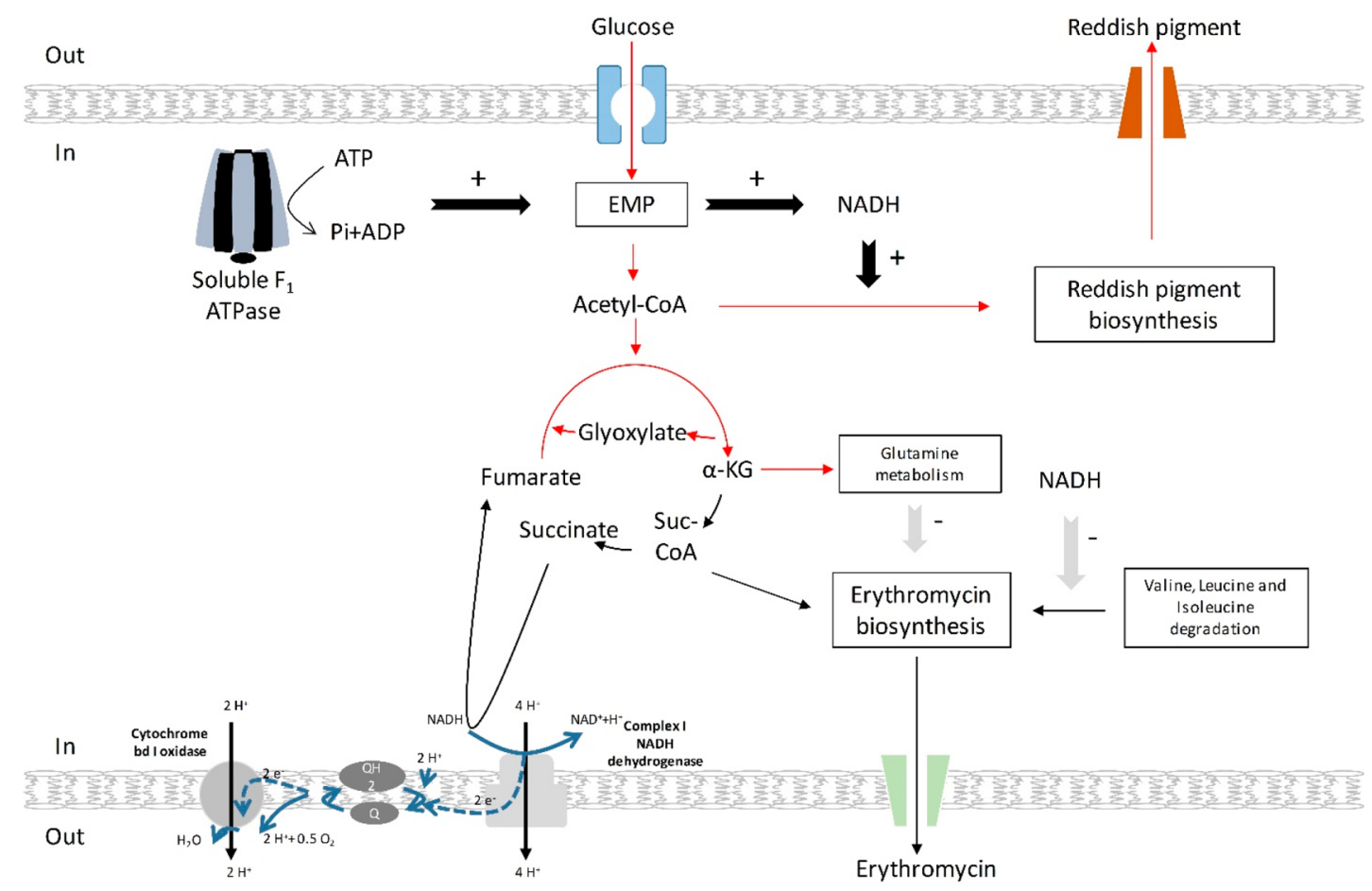

Figure 10. Schematic map of physiological alteration in atpAGD overexpression strain E3:: $\mathrm{F}_{1} \mathrm{ATP}$ ase. EMP, Embden-Meyerhof-Parnas pathway; $\alpha$ KG, $\alpha$-ketoglutarate; Suc-CoA, succinyl-CoA; $\mathrm{QH} 2$, ubiquinol; $\mathrm{Q}$ ubiquinone. The overexpression of soluble $\mathrm{F}_{1}$-ATPase caused lower intracellular $[\mathrm{ATP}] /[\mathrm{ADP}]$ ratios that stimulated the glycolysis flux (Figure 1 and Table 1 ). Accordingly, some genes in the TCA cycle and the glyoxylate shunt were up-regulated instantly (Table S1). More NADH was produced from the glycolysis, the TCA cycle, and the glyoxylate shunt, and the additional $\mathrm{NADH}$ cannot be reoxidized through respiration due to the alteration in the electron transport chain (Table 1 and Figure 7). Consequently, it provoked redox stress in the exponential phase (Figure 2 ). In order to alleviate the stress, the higher $[\mathrm{NADH}] /\left[\mathrm{NAD}^{+}\right]$caused a metabolic shift around acetyl-CoA, from which the enhanced glycolytic flux was led into the reddish pigment synthesis (Figure 5). This shift to bypass some NADH-forming pathways, e.g., valine/leucine/isoleucine degradation together with low flux through succinyl-CoA, reduces the synthesis of erythromycin. Arrows in red indicate pathways with up-regulated fluxes.

Table 4. Strains and Plasmids Used in This Study

\begin{tabular}{|c|c|c|}
\hline designation & genotype or description & reference \\
\hline \multicolumn{3}{|c|}{ S. erythraea Strains } \\
\hline E3 & industrial erythromycin producing strain & our lab \\
\hline $\mathrm{E} 3:: \mathrm{F}_{1} \mathrm{ATPase}$ & $\mathrm{F}_{1}$-ATPase overexpressed in E3, promoted by PermE* & this work \\
\hline $\mathrm{E} 3:: \mathrm{F}_{1} \mathrm{~F}_{0} \mathrm{ATPase}$ & $\mathrm{F}_{1} \mathrm{~F}_{0}-\mathrm{ATPase}$ overexpressed in $\mathrm{E} 3$, promoted by its native promoter & this work \\
\hline \multicolumn{3}{|c|}{ E. coli Strains } \\
\hline top 10 & $\begin{array}{l}\text { F- mcrA } \Delta \text { (mrr-hsdRMS-mcrBC) } \varphi 80 \text { lacZ } \Delta \text { M15 } \Delta \text { lacX74 recA1 ara } \Delta 139 \Delta \text { (ara-leu) } 7697 \text { galU galKrpsL (StrR) endA1 nupG, used for plasmid } \\
\text { constructions }\end{array}$ & \\
\hline ET12567 & $\begin{array}{l}\text { F- dam13::Tn9 dcm-6 hsdM hsdR zjj-202::Tn10 recF143 galK2 galT22 ara-14 lacY1 xyl-5 leuB6 thi-1 tonA31 rpsL136 hisG4 tsx-78 mtl-1 } \\
\text { glnV44, used for conjugation }\end{array}$ & \\
\hline \multicolumn{3}{|c|}{ Plasmids } \\
\hline pIB139 & an integrative plasmid containing oriT, attP, int, aac(3)IV, and ermE* $\mathrm{p}$ & 61 \\
\hline pIB-atpAGD & pIB139 with atpAGD expression under the control of the strong constitutive promoter ermE*p & this work \\
\hline pIB-ATPase & pIB139 with atpBEFHAGDC expression under the control of its native promoter & this work \\
\hline
\end{tabular}

tion. ${ }^{7}$ The secondary metabolic shifts in E3:: $\mathrm{F}_{1}$ ATPase and E3:: $\mathrm{F}_{1} \mathrm{~F}_{0} \mathrm{ATPase}$ indicate that manipulations of intracellular energy state are promising strategies to regulate secondary metabolism without considering the complex transcriptional regulation networks for the gene cluster, ${ }^{59}$ particularly for secondary products with an obscure regulation network.

\section{MATERIALS AND METHODS}

Construction of Plasmids and Strains. Strains and plasmids used in this study are listed in Table 4. Sequences of all of the primers were listed in Table 5. The native coding sequence of atpAGD (SACE_6282-6280) in S. erythraea E3 was amplified using primers, $\overline{6} 282 \mathrm{~F}^{\prime}$ and $6282 \mathrm{R}^{\prime}$, digested by
NdeI and EcoRI, and cloned into digested pIB139, yielding pIBAGD. The entire coding sequence of ATPase atpBEFHAGDC (SACE_6286-6279) and its native promoter region were amplified into two fragments using primers, ATP8F2/atplink1-3 and atplink2-2/ATP8R2. The two fragments were cloned into pIB139 between NsiI and XbaI sites using the GA one-step cloning kit (Synthetic Genomics Inc.), yielding pIB-ATPase. The overexpression mutants E3:: $F_{1}$ ATPase and E3:: $\mathrm{F}_{1} \mathrm{~F}_{0} \mathrm{ATPase}$ were constructed by site-specific chromosomal integration, which is mediated by phiC 31 integrase. E. coli top 10 cells were used for cloning, and ET12567/pUZ8002 was used for conjugation. Plasmids from E. coli ET12567 were then introduced into S. erythraea through transconjugation on ISP4 
Table 5. Primers Used in This Study

\begin{tabular}{|c|c|c|}
\hline designation & sequence $\left(5^{\prime}-3^{\prime}\right)$ & description \\
\hline $6282 \mathrm{~F}^{\prime}$ & GTTGGTAGGATCCACATGGAGCGCTTGCTGTCGGA & for $F_{1}$ part ATPase amplification \\
\hline $6282 \mathrm{R}^{\prime}$ & CTATGACATGATTACGGCGACCAATTGGACGGACAT & \\
\hline ATP8F2 & TGCAGGTCGACTCTAGTATGCATTGAGGTCGTGGGAGGGCTTC & for up fragment of $\mathrm{F}_{1} \mathrm{~F}_{0}$ part ATPase amplification \\
\hline atplink1-2 & СTCTCAGCGCСTTTCACTCATC & \\
\hline atplink2-2 & GATGAGTGAAAGGCGCTGAGAG & for down fragment of $\mathrm{F}_{1} \mathrm{~F}_{0}$ part ATPase amplification \\
\hline ATP8R2 & ATGACATGATTACGAATTCTCAGGACGAGTGTCCGGCC & \\
\hline attBS & GACGCTGTTCCACTCCTACGCC & for PCR confirmation of gene overexpression in S. erythraea \\
\hline attPS & CAGAGCAGGATTCCCGTTGAG & \\
\hline attBA & CGCCCGCCACGTACATCTCA & \\
\hline attPA & CAGGGCGAGCAATTCCGAGA & \\
\hline $\mathrm{BF}$ & ATAGTTTCGTTCTGCCGCCGA & for $\mathrm{qPCR}$ of atpB \\
\hline BR & GCTGAAGTCGTAGATCGACTC & \\
\hline EF & ATCGGTGTCGGTCTGATCT & for qPCR of $a t p E$ \\
\hline ER & TAGACGACCAGACCGATCA & \\
\hline FF & CTGTTCGTGCTCTGGAAGTA & for $\mathrm{qPCR}$ of atpF \\
\hline FR & ACCTGTACTGCTCCAGCGT & \\
\hline $\mathrm{HF}$ & GAAGGACCTGATCAGCGG & for qPCR of $a t p H$ \\
\hline HR & TCCGACAGCAAGCGCTCCA & \\
\hline $\mathrm{AF}$ & ATCTCGTCGGACGAGATCC & for $\mathrm{qPCR}$ of atpA \\
\hline AR & GCAGCTCCTCGGTCATGA & \\
\hline GF & AGGAGCTCATCGCTACCT & for $\mathrm{qPCR}$ of atpG \\
\hline GR & GCAGCACGTTGGCGTTGTA & \\
\hline DF & ATGGCCAAGACCCTGACGCT & for $\mathrm{qPCR}$ of $a t p D$ \\
\hline $\mathrm{DR}$ & TGTCCCTTGACCACGTCACCGA & \\
\hline $\mathrm{CF}$ & TGTGGTCTGGTGAGGCGA & for qPCR of atpC \\
\hline $\mathrm{CR}$ & CGGTGACGGTCTCCTTCT & \\
\hline $8101 \mathrm{~F}$ & GTTGCGATGCCGTGAGGT & for $\mathrm{qPCR}$ of $16 \mathrm{~s} \mathrm{rRNA}$, as inner reference \\
\hline $8101 \mathrm{R}$ & CGGGTGTTACCGACTTTCA & \\
\hline
\end{tabular}

agar medium. ${ }^{60}$ A $30 \mu \mathrm{g}$ portion of apramycin was overlaid on ISP4 plates for screening conjugators. Primers attBS/attPS and attBA/attPA were used for PCR identification of overexpression mutants.

Medium and Culture Conditions. S. erythraea was cultivated on XM agar medium ${ }^{13}$ at $34{ }^{\circ} \mathrm{C}$ for 6 days for spore collection. About $1 \mathrm{~cm}^{2} \mathrm{XM}$ agar medium covered with dense spores was picked into flasks with preculture medium. ${ }^{13}$ After the $48 \mathrm{~h}$ preculture, a $3 \mathrm{~mL}$ preculture was collected,

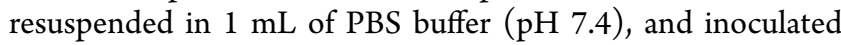
into flasks with either $27 \mathrm{~mL}$ of modified minimal liquid medium for physiological study or complex fermentation medium ${ }^{13}$ for characterization under industrial conditions. The modified minimal liquid medium contained the following per $800 \mathrm{~mL}$ : $20 \mathrm{~g}$ of $\left(\mathrm{NH}_{4}\right)_{2} \mathrm{SO}_{4}, 50 \mathrm{~g}$ of casamino acids (DifcoTM, BD), 0.6 $\mathrm{g}$ of $\mathrm{MgSO}_{4} \cdot 7 \mathrm{H}_{2} \mathrm{O}, 1 \mathrm{~g}$ of $\mathrm{ZnSO}_{4} \cdot 7 \mathrm{H}_{2} \mathrm{O}, 1 \mathrm{~g}$ of $\mathrm{FeSO}_{4} \cdot 7 \mathrm{H}_{2} \mathrm{O}, 1 \mathrm{~g}$ of $\mathrm{MnCl}_{2} \cdot 4 \mathrm{H}_{2} \mathrm{O}, 1 \mathrm{~g}$ of $\mathrm{CaCl}_{2}$. A $800 \mathrm{~mL}$ portion of MMLM was then dispensed in $80 \mathrm{~mL}$ aliquots. A $15 \mathrm{~mL}$ portion of $\mathrm{NaH}_{2} \mathrm{PO}_{4} / \mathrm{K}_{2} \mathrm{HPO}_{4}$ buffer $(0.1 \mathrm{M}, \mathrm{pH} 6.8)$ was added into 80 $\mathrm{mL}$ of liquid medium for $\mathrm{pH}$ buffering. After autoclaving, $25 \%$ $(\mathrm{w} / \mathrm{v})$ glucose as the sole carbon source was injected into the medium to a final concentration of $20 \mathrm{~g} / \mathrm{L}$. Liquid culture was performed in shaking water baths (Julabo, Germany) with an agitation speed of $140 \mathrm{rpm}$ at $34{ }^{\circ} \mathrm{C}$.

To study the effects of a higher $[\mathrm{NADH}] /\left[\mathrm{NAD}^{+}\right]$ratio on secondary metabolism in S. erythraea, various volumes of $50 \mathrm{mM}$ rotenone were added in liquid culture of E3 in the middle exponential phase $(24 \mathrm{~h})$ and in the early stationary phase (48 $\mathrm{h})$. In order to enhance intracellular $[\mathrm{ATP}] /[\mathrm{ADP}]$ ratios, a gradient concentration of apramycin was supplemented in the minimal liquid medium at the start of fermentation. The initial
$\mathrm{OD}_{600}$ of fermentation culture with apramycin was controlled around $0.3-0.4$ at inoculation.

Fermentation Analysis. Cell samples from cultures in duplicate or triplicate shake flask were collected over the time course. Dry cell weight (DCW) in $3 \mathrm{~mL}$ culture was measured for monitoring cell growth. ${ }^{11}$ The concentration of residual glucose in culture was determined by the salicylic acid method. ${ }^{17}$ Each culture sample was centrifuged at $8000 \times g$ at $4{ }^{\circ} \mathrm{C}$ for 10 min, and extracellular organic acids in supernatants were determined using a HPLC (Thermo Scientific, USA). The HPLC detection system included an Aminex HPX-87H column (Bio-Rad, USA) and a Shodex RI-101 detector (Tokyo, Japan). The mobile phase consisted of $5 \mathrm{mM} \mathrm{H}_{2} \mathrm{SO}_{4}$, and the flow rate was set at $0.5 \mathrm{~mL} / \mathrm{min}$. The column oven temperature was 60 ${ }^{\circ} \mathrm{C}$. The dissolved oxygen (DO) concentration was determined using a DO electrode (Endress+Hauser A/S, Denmark). A 25 $\mathrm{mL}$ portion of broth with cells was withdrawn from the flask, washed, and resuspended in $25 \mathrm{~mL}$ of PBS buffer ( $\mathrm{pH} 7.4$ ). Then, the DO value was monitored each $10 \mathrm{~s}$ for a total duration of $5 \mathrm{~min}$. One L bioreactors (Sartorius, Germany) with $0.6 \mathrm{~L}$ working volume were used for monitoring online $\mathrm{pH}$ using electrodes (Endress+Hauser A/S, Denmark). For measuring the reddish pigment in liquid culture, the broth supernatant was diluted 100 times and then was relatively quantified by absorbance at $270 \mathrm{~nm}^{62}$ The erythromycin titer was measured by the modified $\mathrm{H}_{2} \mathrm{SO}_{4}$-colorimetric method. ${ }^{63}$

Analysis of Intracellular Cofactors. For [NADH]/ $\left[\mathrm{NAD}^{+}\right]$determination, cold methanol quenching was applied. Previous reports on actinomycetes suggest leakage caused by cold shock. ${ }^{64}$ Each sample with $50 \mu \mathrm{L}$ cell culture was quenched by immediate addition of $500 \mu \mathrm{L}$ of methanol precooled at -80 
${ }^{\circ} \mathrm{C}$. Portions of $500 \mu \mathrm{L}$ of $4{ }^{\circ} \mathrm{C}$ water and $500 \mu \mathrm{L}$ of $-20{ }^{\circ} \mathrm{C}$ chloroform were instantly added to the samples. Samples was vortexed vigorously and then stored at $-20{ }^{\circ} \mathrm{C}$ for $1 \mathrm{~h}$. Supernatant was reserved by centrifugation at $10000 \times g$ at $4{ }^{\circ} \mathrm{C}$ for $10 \mathrm{~min}$. A NAD/NADH-Glo assay kit (Promega, USA) was used for $\mathrm{NADH} / \mathrm{NAD}^{+}$measurement. For $[\mathrm{ATP}] /[\mathrm{ADP}]$ ratio determination, cells were quenched by phenol as described previously. ${ }^{65}$ The amount of ATP or ADP was quantified with an ATP determination Kit (A22066) (Invitrogen, USA). ADP was assayed after ATP had been determined by adding pyruvate kinase and recording the increase in luminescence. The results were corrected for quenching of the signal by the addition of pyruvate kinase.

Activity Measurement of Enzymes. Cells in the exponential phase $(12 \mathrm{~h})$ were harvested by centrifugation, washed with an appropriate buffer, and kept at $-20{ }^{\circ} \mathrm{C}$ until use. In order to standardize enzymatic activity values, a $3 \mathrm{~mL}$ culture was used for dry cell weight measurement. About $0.5 \mathrm{~g}$ of glass beads was added into another $1 \mathrm{~mL}$ cell culture. The cells were disrupted by a FastPrep ( $30 \mathrm{~s} \times 4$; M.P. Biomedical, USA $)$ and centrifuged at $15,000 \times g$ at $4{ }^{\circ} \mathrm{C}$ for $10 \mathrm{~min}$. The supernatant was used for protein concentration measurement using a Nanodrop One ${ }^{c}$ (Thermo Scientific, USA). The composition of the buffer system, reaction mixtures, and assay conditions for the respective enzymes were described previously. ${ }^{26}$ A $20 \mu \mathrm{L}$ cell extract was added in $1 \mathrm{~mL}$ of reaction mixture. The specific activity of each enzyme under the assay conditions was expressed in $\mathrm{nmol} \cdot \mathrm{min}^{-1} \cdot \mathrm{mg}$ of protein $^{-1}$.

Sequencing of RNA. Two replicates from independent cultures in modified minimal liquid cultures were used. Cells were harvested at two time points, i.e., $10 \mathrm{~h}$ in the early exponential phase and $48 \mathrm{~h}$ at the onset point of erythromycin biosynthesis, for total RNA extraction. A $10 \mathrm{~mL}$ culture was centrifuged at $4000 \times g$ at $4{ }^{\circ} \mathrm{C}$ for $10 \mathrm{~min}$. The supernatant was discarded, and the cells were resuspended in $2 \mathrm{~mL}$ of RNAlater solution (Invitrogen, USA). Total RNA was extracted with an RNAeasy Plus Mini kit (Qiagen, Germany) using glass beads to mechanically disrupt cells with a FastPrep. DNase treatment by an RNase-Free DNase Set (Qiagen, Germany) aided to digest DNA in the samples. The RNA integrality was analyzed by $1 \%$ agarose gel electrophoresis and Bioanalyzer (Agilent, USA). The RNA concentration was also determined by Bioanalyzer (Agilent, USA). A $1 \mu \mathrm{g}$ portion of total RNA was reverse transcribed using a PrimeScript RT Reagent Kit with gDNA Eraser (Takara, Shiga, Japan) for RT-qPCR. Transcriptional levels were quantified in triplicate with $16 \mathrm{~s}$ rRNA gene (SACE_8101) as the inner reference. Primers used for qPCR were listed in Table 2. The $2^{-\Delta \Delta C t}$ method was used for calculating the relative expression. ${ }^{66}$

RNA sequencing was accomplished using the BGIseq 500 next-gen sequencer by BGI, China. Data sets consisted of at least $30 \mathrm{M}$ reads per sample. After sequencing, the raw reads were filtered, including removing adaptor sequences, contamination, and low-quality reads from raw reads.

Transcriptomic Analysis. FastQ files sequenced by BGIseq 500 were input into the software, Geneious Prime, for raw reads mapping into the S. erythraea NRRL2338 genome (GenBank accession number: NC_009142) and were trimmed afterward. The RPKM value of each gene was calculated by Geneious Prime. Differentially expressed genes (DEGs) were identified by using the DEseq2 method. Clusters of orthologous groups were identified in the EggNOG database. ${ }^{67}$ iPATH facilitates visualization of the distribution of DEGs upon different metabolic pathways. ${ }^{45}$ Gene set analysis and reporter metabolite analysis were conducted by $\mathrm{R}$ package Piano $^{68}$ based on a genome-scale metabolic model. ${ }^{15}$ Hierarchical clustering of DEGs was carried out by a web-based tool, Morpheus (https:// software.broadinstitute.org/GENE-E).

Data Availability. Raw reads of RNA sequencing used in this study can be obtained from the NCBI Gene Expression Omnibus (accession number: GSE134767).

\section{ASSOCIATED CONTENT}

\section{Supporting Information}

The Supporting Information is available free of charge at https://pubs.acs.org/doi/10.1021/acssynbio.9b00528.

Figure S1, online $\mathrm{pH}$ curve for the parental strain E3 and atpAGD overexpression strain E3:: $\mathrm{F}_{1}$ ATPase batchcultured in $1 \mathrm{~L}$ bioreactors; Figure S2, physiological characterization of E3 and E3:: $\mathrm{F}_{1}$ ATPase in $300 \mathrm{~mL}$ shake flasks with minimal liquid medium; Figure S3, reporter metabolite analysis based on transcriptomic data derived from the early exponential phase; Table S1, transcription response of some genes involved in the central carbon metabolism (PDF)

Table S2, expression change of NADH-related genes in $\mathrm{E} 3:: \mathrm{F}_{1} \mathrm{ATPase}$ with respect to E3 (XLSX)

\section{AUTHOR INFORMATION}

\section{Corresponding Authors}

Ju Chu - State Key Laboratory of Bioreactor Engineering, East China University of Science and Technology, Shanghai 200237, People's Republic of China; Phone: (+86) 021-64253021; Email: juchu@ecust.edu.cn

Peter R. Jensen - National Food Institute, Technical University of Denmark, DK2800 Kongens Lyngby, Denmark; 이이.org/ 0000-0003-2080-2070; Phone: (+45) 20855601; Email: perj@food.dtu.dk

\section{Authors}

Xiaobo Li - State Key Laboratory of Bioreactor Engineering, East China University of Science and Technology, Shanghai 200237, People's Republic of China; National Food Institute, Technical University of Denmark, DK2800 Kongens Lyngby, Denmark

Jun Chen - National Food Institute, Technical University of Denmark, DK2800 Kongens Lyngby, Denmark

Joakim M. Andersen - National Food Institute, Technical University of Denmark, DK2800 Kongens Lyngby, Denmark

Complete contact information is available at:

https://pubs.acs.org/10.1021/acssynbio.9b00528

\section{Notes}

The authors declare no competing financial interest.

\section{ACKNOWLEDGMENTS}

X.L. and J.C. received funding from the National Natural Science Foundation of China (No. 21276081) and the National Scientific and Technological Major Special Project (Significant Creation of New drugs, No. 2011ZX09203-001-03). We are grateful for the financial support from the program of China Scholarships Council (No. 201706740055) to X.L. The funders had no role in study design, data collection, and interpretation or the decision to submit the work for publication. We thank Tine Suhr for assistance with laboratory work and Yufei Sui for assistance with the transcriptional analysis. 


\section{REFERENCES}

(1) Coates, A. R., and Hu, Y. (2007) Novel approaches to developing new antibiotics for bacterial infections. Br. J. Pharmacol. 152 (8), 114754.

(2) Hong, M., Mou, H., Liu, X., Huang, M., and Chu, J. (2017) (13)Cassisted metabolomics analysis reveals the positive correlation between specific erythromycin production rate and intracellular propionyl-CoA pool size in Saccharopolyspora erythraea. Bioprocess Biosyst. Eng. 40 (9), $1337-1348$

(3) Mittal, N., Tesfu, H. H., Hogan, A. M., Cardona, S. T., and Sorensen, J. L. (2019) Synthesis and antibiotic activity of novel acylated phloroglucinol compounds against methicillin-resistant Staphylococcus aureus. J. Antibiot. 72 (5), 253-259.

(4) Gomez-Escribano, J. P., and Bibb, M. J. (2014) Heterologous expression of natural product biosynthetic gene clusters in Streptomyces coelicolor: from genome mining to manipulation of biosynthetic pathways. J. Ind. Microbiol. Biotechnol. 41 (2), 425-31.

(5) Leadlay, P. F. (1997) Combinatorial approaches to polyketide biosynthesis. Curr. Opin. Chem. Biol. 1 (2), 162-168.

(6) Oliynyk, M., Samborskyy, M., Lester, J. B., Mironenko, T., Scott, N., Dickens, S., Haydock, S. F., and Leadlay, P. F. (2007) Complete genome sequence of the erythromycin-producing bacterium Saccharopolyspora erythraea NRRL23338. Nat. Biotechnol. 25 (4), 447-53.

(7) Cortés, J., Velasco, J., Foster, G., Blackaby, A. P., Rudd, B. A., and Wilkinson, B. (2002) Identification and cloning of a type III polyketide synthase required for diffusible pigment biosynthesis in Saccharopolyspora erythraea. Mol. Microbiol. 44 (5), 1213-1224.

(8) Butler, M. J., Bruheim, P., Jovetic, S., Marinelli, F., Postma, P. W., and Bibb, M. J. (2002) Engineering of primary carbon metabolism for improved antibiotic production in Streptomyces lividans. Appl. Environ. Microbiol. 68 (10), 4731-9.

(9) Liao, C. H., Xu, Y., Rigali, S., and Ye, B. C. (2015) DasR is a pleiotropic regulator required for antibiotic production, pigment biosynthesis, and morphological development in Saccharopolyspora erythraea. Appl. Microbiol. Biotechnol. 99 (23), 10215-24.

(10) Carata, E., Peano, C., Tredici, S. M., Ferrari, F., Tala, A., Corti, G., Bicciato, S., De Bellis, G., and Alifano, P. (2009) Phenotypes and gene expression profiles of Saccharopolyspora erythraea rifampicin-resistant (rif) mutants affected in erythromycin production. Microb. Cell Fact. 8, 18.

(11) Borodina, I., Siebring, J., Zhang, J., Smith, C. P., van Keulen, G., Dijkhuizen, L., and Nielsen, J. (2008) Antibiotic overproduction in Streptomyces coelicolor A3 2 mediated by phosphofructokinase deletion. J. Biol. Chem. 283 (37), 25186-99.

(12) Ryu, Y. G., Butler, M. J., Chater, K. F., and Lee, K. J. (2006) Engineering of primary carbohydrate metabolism for increased production of actinorhodin in Streptomyces coelicolor. Appl. Environ. Microbiol. 72 (11), 7132-9.

(13) Chen, C., Hong, M., Chu, J., Huang, M., Ouyang, L., Tian, X., and Zhuang, Y. (2017) Blocking the flow of propionate into TCA cycle through a mutB knockout leads to a significant increase of erythromycin production by an industrial strain of Saccharopolyspora erythraea. Bioprocess Biosyst. Eng. 40 (2), 201-209.

(14) Licona-Cassani, C., Marcellin, E., Quek, L. E., Jacob, S., and Nielsen, L. K. (2012) Reconstruction of the Saccharopolyspora erythraea genome-scale model and its use for enhancing erythromycin production. Antonie van Leeuwenhoek 102 (3), 493-502.

(15) Zhuang, Z., Huang, M., and Chu, J. (2018) In silico reconstruction and experimental validation of Saccharopolyspora erythraea genome-scale metabolic model iZZ1342 that accounts for 1685 ORFs. Bioresour Bioprocess 5 (1), 26.

(16) Scott, R. I., Salmon, I., and Poole, R. K. (1992) The cytochromes of the filamentous bacteria Streptomyces clavuligerus and Saccharopolyspora erythraea (FormerlyStreptomyces erythraeus). Curr. Microbiol. 24 (2), 105-109.

(17) Zou, X., Hang, H.-f., Chu, J., Zhuang, Y.-p., and Zhang, S.-l. (2009) Oxygen uptake rate optimization with nitrogen regulation for erythromycin production and scale-up from $50 \mathrm{~L}$ to $372 \mathrm{~m} 3$ scale. Bioresour. Technol. 100 (3), 1406-1412.
(18) Li, Y.-Y., Chang, X., Yu, W.-B., Li, H., Ye, Z.-Q., Yu, H., Liu, B.-H., Zhang, Y., Zhang, S.-L., and Ye, B.-C. (2013) Systems perspectives on erythromycin biosynthesis by comparative genomic and transcriptomic analyses of S. erythraea E3 and NRRL23338 strains. BMC Genomics 14 (1), 523.

(19) Chen, Y., Wang, Z., Chu, J., Xi, B., and Zhuang, Y. (2015) The glucose RQ-feedback control leading to improved erythromycin production by a recombinant strain Saccharopolyspora erythraea ZL1004 and its scale-up to 372-m(3) fermenter. Bioprocess Biosyst. Eng. 38 (1), 105-12.

(20) Li, M., Kim, T. J., Kwon, H. J., and Suh, J. W. (2008) Effects of extracellular ATP on the physiology of Streptomyces coelicolor A3(2). FEMS Microbiol. Lett. 286 (1), 24-31.

(21) Koebmann, B. J., Westerhoff, H. V., Snoep, J. L., Nilsson, D., and Jensen, P. R. (2002) The Glycolytic Flux in Escherichia coli Is Controlled by the Demand for ATP. J. Bacteriol. 184 (14), 3909-3916.

(22) Larsson, C., Nilsson, A., Blomberg, A., and Gustafsson, L. (1997) Glycolytic flux is conditionally correlated with ATP concentration in Saccharomyces cerevisiae: a chemostat study under carbon-or nitrogenlimiting conditions. J. Bacteriol. 179 (23), 7243-7250.

(23) Lan, E. I., and Liao, J. C. (2012) ATP drives direct photosynthetic production of 1-butanol in cyanobacteria. Proc. Natl. Acad. Sci. U. S. A. 109 (16), 6018-6023.

(24) Liu, J., Wang, Z., Kandasamy, V., Lee, S. Y., Solem, C., and Jensen, P. R. (2017) Harnessing the respiration machinery for high-yield production of chemicals in metabolically engineered Lactococcus lactis. Metab. Eng. 44, 22-29.

(25) Liu, J., Kandasamy, V., Wurtz, A., Jensen, P. R., and Solem, C. (2016) Stimulation of acetoin production in metabolically engineered Lactococcus lactis by increasing ATP demand. Appl. Microbiol. Biotechnol. 100 (22), 9509-9517.

(26) Noda, S., Takezawa, Y., Mizutani, T., Asakura, T., Nishiumi, E., Onoe, K., Wada, M., Tomita, F., Matsushita, K., and Yokota, A. (2006) Alterations of cellular physiology in Escherichia coli in response to oxidative phosphorylation impaired by defective F1-ATPase. J. Bacteriol. 188 (19), 6869-76.

(27) Holm, A. K., Blank, L. M., Oldiges, M., Schmid, A., Solem, C., Jensen, P. R., and Vemuri, G. N. (2010) Metabolic and transcriptional response to cofactor perturbations in Escherichia coli. J. Biol. Chem. 285 (23), 17498-506.

(28) Jensen, P. R., and Michelsen, O. (1992) Carbon and energy metabolism of atp mutants of Escherichia coli. J. Bacteriol. 174 (23), $7635-7641$.

(29) Jensen, P. R., Michelsen, O., and Westerhoff, H. V. (1993) Control analysis of the dependence of Escherichia coli physiology on the H (+)-ATPase. Proc. Natl. Acad. Sci. U. S. A. 90 (17), 8068-8072.

(30) Koebmann, B. J., Solem, C., Pedersen, M. B., Nilsson, D., and Jensen, P. R. (2002) Expression of Genes Encoding F1-ATPase Results in Uncoupling of Glycolysis from Biomass Production in Lactococcus lactis. Appl. Environ. Microbiol. 68 (9), 4274-4282.

(31) Chen, Y., and Tan, T. (2018) Enhanced S-Adenosylmethionine Production by Increasing ATP Levels in Baker's Yeast (Saccharomyces cerevisiae). J. Agric. Food Chem. 66 (20), 5200-5209.

(32) Yokota, A., Henmi, M., Takaoka, N., Hayashi, C., Takezawa, Y., Fukumori, Y., and Tomita, F. (1997) Enhancement of glucose metabolism in a pyruvic acid-hyperproducing Escherichia coli mutant defective in F1-ATPase activity. J. Ferment. Bioeng. 83 (2), 132-138.

(33) Siegl, T., Tokovenko, B., Myronovskyi, M., and Luzhetskyy, A. (2013) Design, construction and characterisation of a synthetic promoter library for fine-tuned gene expression in actinomycetes. Metab. Eng. 19, 98-106.

(34) Chen, Y., Huang, M., Wang, Z., Chu, J., Zhuang, Y., and Zhang, S. (2013) Controlling the feed rate of glucose and propanol for the enhancement of erythromycin production and exploration of propanol metabolism fate by quantitative metabolic flux analysis. Bioprocess Biosyst. Eng. 36 (10), 1445-53.

(35) Jensen, P. R., Westerhoff, H. V., and Michelsen, O. (1993) Excess capacity of $\mathrm{H}(+)$-ATPase and inverse respiratory control in Escherichia coli. EMBO J. 12 (4), 1277-1282. 
(36) Qin, Y., Dong, Z., Liu, L., and Chen, J. (2009) Manipulation of $\mathrm{NADH}$ metabolism in industrial strains. Shengwu Gongcheng Xuebao 25 (2), 161-169.

(37) Berríos-Rivera, S. (2002) The Effect of Increasing NADH Availability on the Redistribution of Metabolic Fluxes in Escherichia coli Chemostat Cultures. Metab. Eng. 4 (3), 230-237.

(38) Zhuang, Y., Chu, J., Zhang, S., Zhao, J., and Yang, S. (2004) Parameter Correlation Analysis and optimization of Process in the Early Period of Erythromycin Fermentation. J. East China Univ. Sci. Technol. 30 (6), 636-639.

(39) Vemuri, G. N., Eiteman, M. A., McEwen, J. E., Olsson, L., and Nielsen, J. (2007) Increasing NADH oxidation reduces overflow metabolism in Saccharomyces cerevisiae. Proc. Natl. Acad. Sci. U. S. A. 104 (7), 2402-7.

(40) Reeves, A. R., Brikun, I. A., Cernota, W. H., Leach, B. I., Gonzalez, M. C., and Weber, J. M. (2007) Engineering of the methylmalonyl-CoA metabolite node of Saccharopolyspora erythraea for increased erythromycin production. Metab. Eng. 9 (3), 293-303.

(41) Kroeger, J. K., Zarzycki, J., and Fuchs, G. (2011) A spectrophotometric assay for measuring acetyl-coenzyme A carboxylase. Anal. Biochem. 411 (1), 100-5.

(42) Liu, L., Li, Y., Li, H., and Chen, J. (2006) Significant increase of glycolytic flux in Torulopsis glabrata by inhibition of oxidative phosphorylation. FEMS Yeast Res. 6 (8), 1117-29.

(43) Karnicar, K., Drobnak, I., Petek, M., Magdevska, V., Horvat, J., Vidmar, R., Baebler, S., Rotter, A., Jamnik, P., Fujs, S., Turk, B., Fonovic, M., Gruden, K., Kosec, G., and Petkovic, H. (2016) Integrated omics approaches provide strategies for rapid erythromycin yield increase in Saccharopolyspora erythraea. Microb. Cell Fact. 15, 93.

(44) Xu, Z., You, D., Tang, L. Y., Zhou, Y., and Ye, B. C. (2019) Metabolic engineering strategies based on secondary messengers (p)ppGpp and C-di-GMP to increase erythromycin yield in Saccharopolyspora erythraea. ACS Synth. Biol. 8 (2), 332-345.

(45) Darzi, Y., Letunic, I., Bork, P., and Yamada, T. (2018) iPath3.0: interactive pathways explorer v3. Nucleic Acids Res. 46 (W1), W510W513.

(46) Hong, M., Huang, M., Chu, J., Zhuang, Y., and Zhang, S. (2016) Impacts of proline on the central metabolism of an industrial erythromycin-producing strain Saccharopolyspora erythraea via (13) C labeling experiments. J. Biotechnol. 231, 1-8.

(47) Niebisch, A., and Bott, M. (2003) Purification of a cytochrome bc-aa3 supercomplex with quinol oxidase activity from Corynebacterium glutamicum. Identification of a fourth subunity of cytochrome aa3 oxidase and mutational analysis of diheme cytochrome c1. J. Biol. Chem. 278 (6), 4339-46.

(48) Fujimoto, M., Chijiwa, M., Nishiyama, T., Takano, H., and Ueda, K. (2016) Developmental defect of cytochrome oxidase mutants of Streptomyces coelicolor A3(2). Microbiology 162 (8), 1446-1455.

(49) Qiao, K., Wasylenko, T. M., Zhou, K., Xu, P., and Stephanopoulos, G. (2017) Lipid production in Yarrowia lipolytica is maximized by engineering cytosolic redox metabolism. Nat. Biotechnol. 35 (2), 173-177.

(50) Fischer, M., Falke, D., Naujoks, C., and Sawers, R. G. (2018) Cytochrome bd oxidase has an important role in sustaining growth and development of Streptomyces coelicolor A3 (2) under oxygen-limiting conditions. J. Bacteriol. 200 (16), e00239-18.

(51) Man, Z., Rao, Z., Xu, M., Guo, J., Yang, T., Zhang, X., and Xu, Z. (2016) Improvement of the intracellular environment for enhancing 1 arginine production of Corynebacterium glutamicum by inactivation of $\mathrm{H} 2 \mathrm{O} 2$-forming flavin reductases and optimization of ATP supply. Metab. Eng. 38, 310-321.

(52) Severi, E., and Thomas, G. H. (2019) Antibiotic export: transporters involved in the final step of natural product production. Microbiology 165, 805-818.

(53) Ghorbel, S., Smirnov, A., Chouayekh, H., Sperandio, B., Esnault, C., Kormanec, J., and Virolle, M. J. (2006) Regulation of ppk expression and in vivo function of Ppk in Streptomyces lividans TK24. J. Bacteriol. 188 (17), 6269-76.
(54) Chouayekh, H., and Virolle, M. J. (2002) The polyphosphate kinase plays a negative role in the control of antibiotic production in Streptomyces lividans. Mol. Microbiol. 43 (4), 919-930.

(55) Peano, C., Damiano, F., Forcato, M., Pietrelli, A., Palumbo, C., Corti, G., Siculella, L., Fuligni, F., Tagliazucchi, G. M., De Benedetto, G. E., Bicciato, S., De Bellis, G., and Alifano, P. (2014) Comparative genomics revealed key molecular targets to rapidly convert a reference rifamycin-producing bacterial strain into an overproducer by genetic engineering. Metab. Eng. 26, 1-16.

(56) Meng, L., Li, M., Yang, S. H., Kim, T. J., and Suh, J. W. (2011) Intracellular ATP levels affect secondary metabolite production in Streptomyces spp. Biosci., Biotechnol., Biochem. 75 (8), 1576-81.

(57) Radchenko, M. V., Thornton, J., and Merrick, M. (2013) P(II) signal transduction proteins are ATPases whose activity is regulated by 2-oxoglutarate. Proc. Natl. Acad. Sci. U. S. A. 110 (32), 12948-53.

(58) Chng, C., Lum, A. M., Vroom, J. A., and Kao, C. M. (2008) A key developmental regulator controls the synthesis of the antibiotic erythromycin in Saccharopolyspora erythraea. Proc. Natl. Acad. Sci. U. S. A. 105 (32), 11346-51.

(59) Wei, J., He, L., and Niu, G. (2018) Regulation of antibiotic biosynthesis in actinomycetes: perspectives and challenges. Synth Syst. Biotechnol 3 (4), 229-235.

(60) Hopwood, D., Bibb, M., Chater, K., Kieser, T., Bruton, C., Kieser, H., Lydiate, D., Smith, C., Ward, J., and Schrempf, H. (1985) Genetic Manipulation of Streptomyces: A Laboratory Manual, John Innes Foundation, Norwich, U.K.

(61) Wilkinson, C. J., Hughes-Thomas, Z. A., Martin, C. J., Bohm, I., Mironenko, T., Deacon, M., Wheatcroft, M., Wirtz, G., Staunton, J., and Leadlay, P. F. (2002) Increasing the efficiency of heterologous promoters in actinomycetes. J. Mol. Microbiol. Biotechnol. 4 (4), 417426.

(62) Magdevska, V., Gaber, R., Goranovic, D., Kuscer, E., Boakes, S., Duran Alonso, M. B., Santamaria, R. I., Raspor, P., Leadlay, P. F., Fujs, S., and Petkovic, H. (2010) Robust reporter system based on chalcone synthase rppA gene from Saccharopolyspora erythraea. J. Microbiol. Methods 83 (2), 111-9.

(63) Zou, X., Hang, H.-f., Chu, J., Zhuang, Y.-p., and Zhang, S.-1. (2009) Enhancement of erythromycin A production with feeding available nitrogen sources in erythromycin biosynthesis phase. Bioresour. Technol. 100 (13), 3358-3365.

(64) Wittmann, C., Kromer, J. O., Kiefer, P., Binz, T., and Heinzle, E. (2004) Impact of the cold shock phenomenon on quantification of intracellular metabolites in bacteria. Anal. Biochem. 327 (1), 135-9.

(65) Michel, A., Koch-Koerfges, A., Krumbach, K., Brocker, M., and Bott, M. (2015) Anaerobic growth of Corynebacterium glutamicum via mixed-acid fermentation. Appl. Environ. Microbiol. 81 (21), 7496-7508.

(66) Livak, K. J., and Schmittgen, T. D. (2001) Analysis of relative gene expression data using real-time quantitative PCR and the 2(-Delta Delta C(T)) Method. Methods 25 (4), 402-8.

(67) Huerta-Cepas, J., Szklarczyk, D., Forslund, K., Cook, H., Heller, D., Walter, M. C., Rattei, T., Mende, D. R., Sunagawa, S., and Kuhn, M. (2016) eggNOG 4.5: a hierarchical orthology framework with improved functional annotations for eukaryotic, prokaryotic and viral sequences. Nucleic Acids Res. 44 (D1), D286-D293.

(68) Varemo, L., Nielsen, J., and Nookaew, I. (2013) Enriching the gene set analysis of genome-wide data by incorporating directionality of gene expression and combining statistical hypotheses and methods. Nucleic Acids Res. 41 (8), 4378-91. 